\title{
The behaviour of thermoplastic and thermoset carbon fibre composites subjected to low-velocity and high- velocity impact
}

\author{
Haibao Liu', Jun Liu', Yuzhe Ding ${ }^{1}$, Jie Zheng ${ }^{2}$, Xiangshao Kong ${ }^{3}$, Jin Zhou ${ }^{4}$, \\ Lee Harper ${ }^{5}$, Bamber R. K. Blackman ${ }^{1}$, Anthony J. Kinloch ${ }^{1, \star}$, and John P. Dear ${ }^{1, \star}$ (1) \\ ${ }^{1}$ Department of Mechanical Engineering, Imperial College London, London SW7 2AZ, UK \\ ${ }^{2}$ The First Aircraft Institute, No.1 East Renmin Road, Yanliang District, Xi'an 710089, Shaanxi, People's Republic of China \\ ${ }^{3}$ Ocean and Structural Engineering, Departments of Naval Architecture, School of Transportation, Wuhan University of \\ Technology, Wuhan, Hubei 430063, People's Republic of China \\ ${ }^{4}$ School of Mechanical Engineering, Xi'an Jiaotong University, Xi'an 710049, Shaanxi, People's Republic of China \\ ${ }^{5}$ Composites Research Group, Faculty of Engineering, University of Nottingham, Nottingham, UK
}

Received: 30 April 2020

Accepted: 18 August 2020

Published online:

1 September 2020

(C) The Author(s) 2020

\begin{abstract}
The present paper describes the results from experimental and theoretical modelling studies on the behaviour of continuous carbon fibre/polymer matrix composites subjected to a relatively low-velocity or high-velocity impact, using a rigid, metallic impactor. Drop-weight and gas-gun tests are employed to conduct the low-velocity and high-velocity impact experiments, respectively. The carbon fibre composites are based upon a thermoplastic poly(ether-ether ketone) matrix (termed CF/PEEK) or a thermoset toughened epoxy matrix (termed $\mathrm{CF} /$ Epoxy), which has the same fibre architecture of a cross-ply $\left[0_{3} /\right.$ $\left.90_{3}\right]_{2 \mathrm{~s}}$ lay-up. The studies clearly reveal that the CF/PEEK composites exhibit the better impact performance. Also, at the same impact energy of $10.5 \pm 0.3 \mathrm{~J}$, the relatively high-velocity test at $54.4 \pm 1.0 \mathrm{~m} \mathrm{~s}^{-1}$ leads to more damage in both types of composite than observed from the low-velocity test where the impactor struck the composites at $2.56 \mathrm{~m} \mathrm{~s}^{-1}$. The computationally efficient, two-dimensional, elastic, finite element model that has been developed is generally successful in capturing the essential details of the impact test and the impact damage in the composites, and has been used to predict the loading response of the composites under impact loading.
\end{abstract}

Handling Editor: Avinash Dongare.

Address correspondence to E-mail: a.kinloch@imperial.ac.uk; j.dear@imperial.ac.uk 


\section{Introduction}

High-performance, continuous fibre-reinforced thermoplastic matrix composites, such as carbon fibrereinforced poly(ether-ether ketone) (CF/PEEK), are being used increasingly in the aeronautical, automotive and marine industries due to their excellent mechanical properties [1]. In particular, their high strength-to-weight ratio and high stiffness-to-weight ratio are important attributes. In addition to their good mechanical performance, these thermoplastic matrix composites also typically possess relatively low moisture uptake, high-temperature resistance and recyclability for structural components. Of particular concern for the increasing use of polymer matrix fibre composites in structural engineering applications is the impact resistance of all types of continuous carbon fibre-reinforced polymers (CFRPs), whether based on thermoplastic or thermosetting polymer matrices.

Considering the previous research [e.g. 2-19] on the impact resistance of thermoplastic matrix composites relevant to the themes of the present paper, then as early as 1985 researchers [2-4] first reported that $\mathrm{CF} / \mathrm{PEEK}$ composites possessed a superior resistance to impact damage, when subjected to an impact loading at relatively low energy levels of up to $12 \mathrm{~J}$, compared with the then currently available CFRPs which employed a matrix of a relatively very brittle, thermosetting epoxy polymer (i.e. CF/Epoxy). More detailed studies by Nixon et al. [5] reported on a CF/PEEK laminate, with a $[0 / 90]_{10 \text { s }}$ lay-up, which was evaluated using impact energies of between about 3 and $9 \mathrm{~J}$, which corresponded to impact velocities of between 0.9 and $1.5 \mathrm{~m} \mathrm{~s}^{-1}$. They found that the onset of delamination damage at these relatively low-velocity drop-weight impact tests was associated with a critical level of impact energy. Also, Ghaseminejhad and Parvizi-Majidi [8] have conducted drop-weight impact tests on two different thermoplastic matrix CFRPs, i.e. a woven carbon fibre-reinforced poly(ether-ether ketone) (PEEK) and a woven carbon fibre-reinforced poly(phenylene sulphide) (PPS), to assess their impact performance and damage tolerance. Experiments were performed at three different impact energy levels of between 6.5 and $30 \mathrm{~J}$, at a constant impact velocity of $12.5 \mathrm{~m} \mathrm{~s}^{-1}$, as well as at three different impact velocities with a constant impact energy of $22.6 \mathrm{~J}$. The results suggested that the effects of the impact velocity were not significant over the range investigated, whilst the level of impact energy used greatly influenced the impact response of the thermoplastic composite. However, these authors used only a drop-weight test and thus the range of impact velocities, with a constant impact energy of $22.6 \mathrm{~J}$, that they could study was very limited and only ranged from 1.6 to $3.4 \mathrm{~m} \mathrm{~s}^{-1}$. More recently, Vieille et al. [12] have carried out an experimental study to compare the performances of a carbon fibre epoxy matrix (CF/ Epoxy), a CF/PPS and a CF/PEEK composite, all with a woven fibre architecture, when subjected to a relatively low-velocity impact using a drop-weight test with an impact energy range of about 1.7-25 J, which corresponded to a range of impact velocities of $1.4-5 \mathrm{~m} \mathrm{~s}^{-1}$. They found that the CF/Epoxy composite experienced a larger area of delamination damage compared with the thermoplastic matrix $\mathrm{CF}$ / PPS and CF/PEEK composites. They suggested that this reflected the tougher nature of the thermoplastic PPS and PEEK matrices compared with the thermosetting epoxy matrix.

Now, although there has been extensive research on the relatively low-velocity impact on thermoplastic and thermoset matrix CFRP composites, relatively few studies [e.g. 14-19] have examined the high-velocity impact of such materials, using for example a gas-gun to achieve relatively high impact velocities, and most of this research has concentrated on using a soft projectile, e.g. gelatine, to simulate a bird strike. Indeed, the very few studies [e.g. 18, 19] that have used a hard impactor fired at relatively high velocities have reached somewhat different conclusions. For example, Morita et al. [18] reported that a CF/ Epoxy composite had a slightly better impact resistance compared with a CF/PEEK composite when impacted at energy levels up to $16 \mathrm{~J}$, corresponding to an impact velocity of $130 \mathrm{~m} \mathrm{~s}^{-1}$. However, Wagner et al. [19] found that there was a similar impact behaviour for CF/PEEK and CF/Epoxy composites at relatively high impact energies and velocities of about $150 \mathrm{~J}$ and $75 \mathrm{~m} \mathrm{~s}^{-1}$, respectively. However, somewhat less delamination did occur in the CF/ PEEK composites when lower impact energies of about 40 to $60 \mathrm{~J}$ were employed, which corresponded to impact velocities of about 40 to $50 \mathrm{~m} \mathrm{~s}^{-1}$. Also, there has been relatively little research on comparing the effects of changing the impact velocity and energy levels over a relatively wider range when using a 
rigid impactor, which might arise from debris or tool impacts, to strike a CF/PEEK thermoplastic composite and a CF/Epoxy thermoset composite with the same fibre architecture; and then to develop a numerical model to simulate and quantitatively predict such effects, especially when a toughened thermosetting epoxy matrix is employed in the CFRP, compared with the earlier very brittle epoxy matrices.

Thus, in the present study, low- and high-velocity impact experiments are performed using a rigid impactor, at different energy levels. For the low-velocity impact studies, the present work has employed a drop-weight test and focused on an impact energy range of between 4.5 and $10.5 \mathrm{~J}$, using impact velocities between 1.68 and $2.56 \mathrm{~m} \mathrm{~s}^{-1}$. Such tests lead to a significant extent of impact damage and have an impact energy similar in value to that associated with a strike from typical runway debris. For the highvelocity tests, a gas-gun has been employed giving an impact energy of $10.5 \mathrm{~J}$, so that the results may be directly compared with those from the low-velocity tests, and the impact velocity used for the gas-gun tests is about $54.4 \mathrm{~m} \mathrm{~s}^{-1}$. These low- and high-velocity impact experiments are conducted using a thermoplastic CF/PEEK composite and a toughened thermoset CF/Epoxy composite which possess the same cross-ply lay-up of $\left[0_{3} / 90_{3}\right]_{2 s}$. In particular, for the high-velocity gas-gun experiments, the novel technique of 3D digital image correlation (DIC), coupled with high-speed cameras, has been employed to measure the out-of-plane displacement of the rear face of the composite specimens during the impact event. An elastic, two-dimensional, finite element (FE) model, which is computationally efficient, has been developed to simulate both the lowand high-velocity impact test results. The FE numerical modelling results are quantitatively validated against the experimentally measured impact responses of the composites, which enables the model to be used with confidence (a) to simulate aspects of the high-velocity tests that cannot be directly measured and (b) to be employed in future industrial applications.

\section{Materials}

For the present research, unidirectional 'AS4' carbon fibre-reinforced poly(ether-ether ketone) (CF/PEEK) prepregs, supplied by Cytec Industries, USA, and unidirectional 'T700' carbon fibre-reinforced epoxy (CF/Epoxy) prepregs, supplied by AVIC Composite Corporation, China, were used to fabricate the thermoplastic matrix and thermoset matrix composite laminate plates, respectively. In the case of the CF/ Epoxy prepregs, 25 wt \% of a thermoplastic poly(ether sulphone) toughening agent was present in the epoxy matrix to toughen the thermosetting epoxy matrix polymer. The thermoplastic and thermoset composites were prepared using the same lay-up of $\left[0_{3} / 90_{3}\right]_{2 s}$, with the $0^{\circ}$ plies laid along the longer dimension of the rectangular specimens, and they also possessed the same nominal overall thickness of $3 \mathrm{~mm}$. Both the CF/PEEK and CF/Epoxy laminates had a similar fibre volume fraction, being 0.60 for the CF/PEEK and 0.62 for the CF/Epoxy, and the 'AS4' and the 'T700' carbon fibres have a similar Young's modulus of about $230 \mathrm{GPa}$. The CF/PEEK laminates were fabricated at the University of Nottingham (UK) using a hot press (Mackey Bowley, UK) and the CF/ Epoxy laminates were manufactured by the AVIC Composite Corporation (China) using an autoclave (Beian, China). The jigs and processing details for these thermoplastic and thermoset matrix composites are shown in Fig. 1. The composite test specimens used in both the low-velocity (drop-weight) impact and the high-velocity (gas-gun) impact experiments were machined from the composite laminate plates using a fine-toothed band saw. The dimensions of the composite test specimens were $150 \mathrm{~mm} \times 100 \mathrm{~mm}$, as defined in the ASTM D7316 standard [20], and are shown schematically in Fig. 2a, with the dimensions defined in Table 1.

\section{Experimental procedures}

\section{Introduction}

The experimental procedures for the drop-weight and gas-gun impact experiments are described in detail elsewhere [21], and only the essential details are therefore given below.

\section{Drop-weight (low-velocity) experiments}

The drop-weight impact experiments were performed using an 'Instron 9340' drop tower (CEAST, Italy), with an instrumented stainless steel impactor having a hemispherical head with a diameter of 


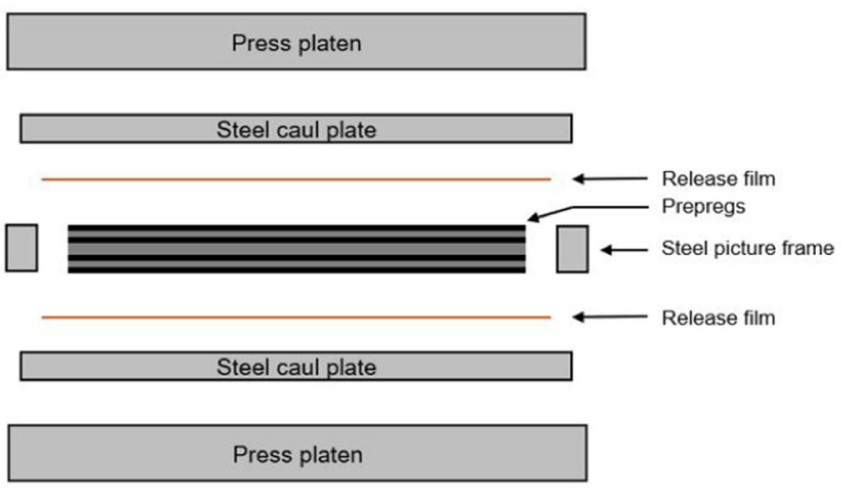

(a)

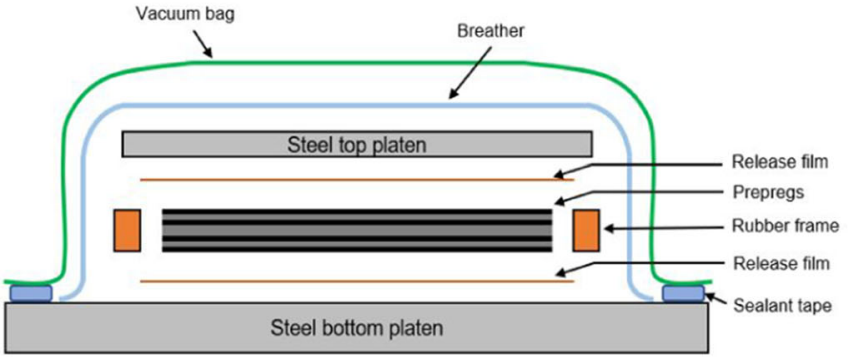

(b)
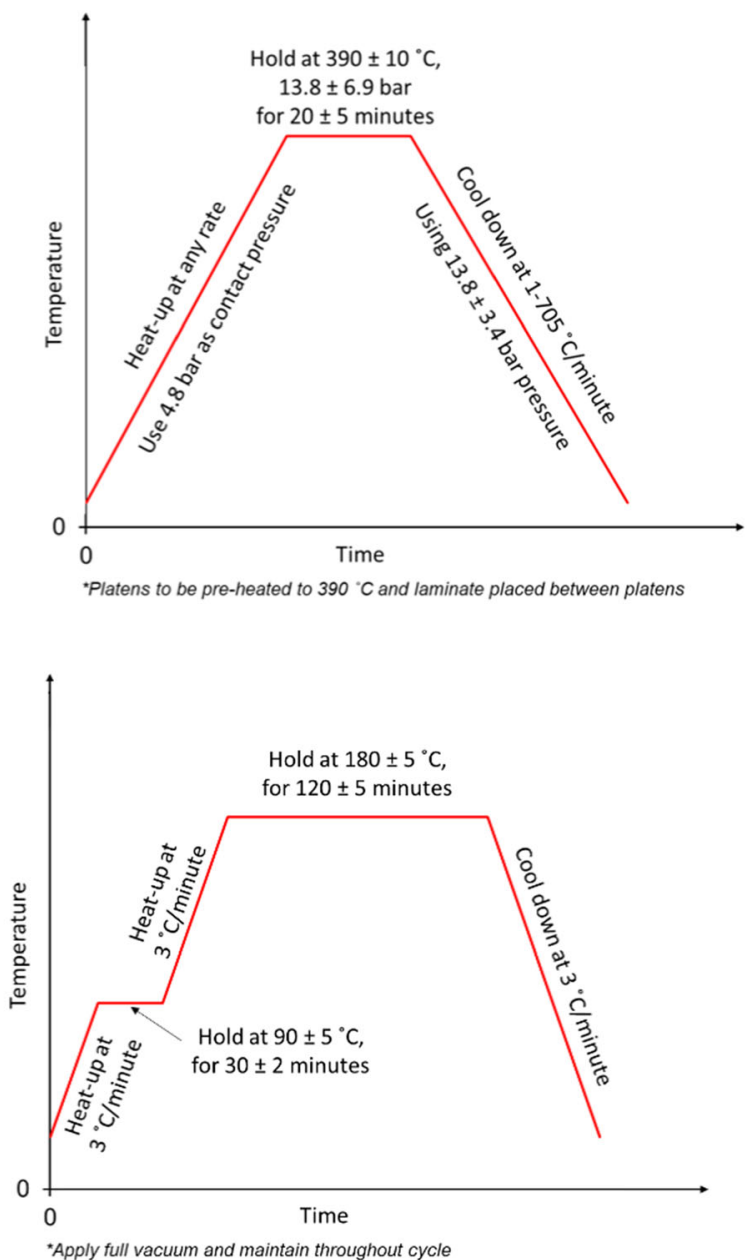

Figure 1 Diagrams of the consolidation jig and the processing cycles for $\mathbf{a}$ the CF/PEEK prepregs and $\mathbf{b}$ the CF/Epoxy prepregs.

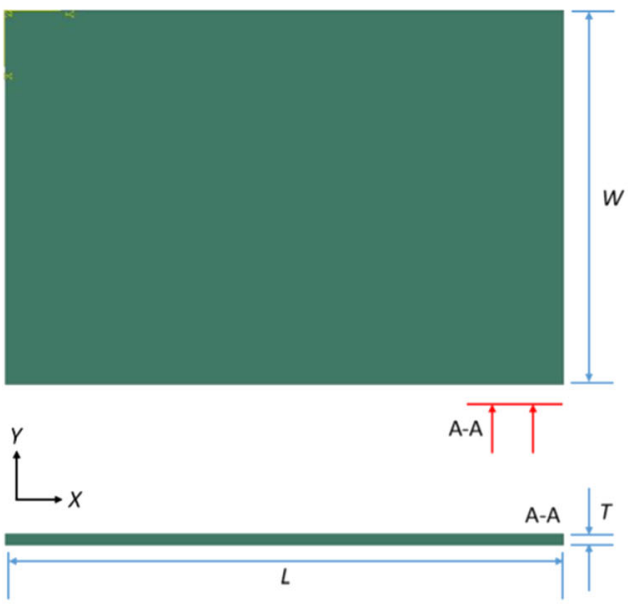

(a)

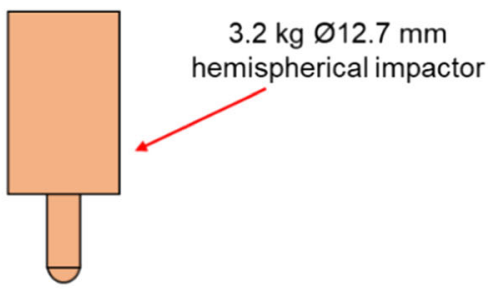

Specimen

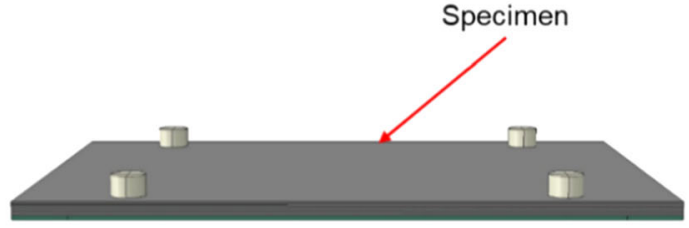

(b)

Figure 2 a Composite test specimen with a lay-up of $\left[0_{3} / 90_{3}\right]_{2 s}$, with the $0^{\circ}$ layer laid along the lengthwise dimension of the rectangular specimens (see Table 1 for dimensions) and $\mathbf{b}$ a schematic of the composite test specimen placed as in the drop-weight test. 
Table 1 Lay-up and dimensions of the composite specimens

\begin{tabular}{llll}
\hline Lay-up & Length $(L)$ & Width $(W)$ & Thickness $(T)$ \\
\hline$\left[0_{3} / 90_{3}\right]_{2 \mathrm{~s}}$ & $150 \mathrm{~mm}$ & $100 \mathrm{~mm}$ & $3 \mathrm{~mm}$ \\
\hline
\end{tabular}

$12.7 \mathrm{~mm}$. The impactor had an overall mass of $3.2 \mathrm{~kg}$. The load cell, with a data sampling rate of $500 \mathrm{kHz}$, was located in the forward section of the impactor. Each composite specimen was placed on a steel picture frame which had outer dimensions that matched those of the composite specimens and with a $125 \mathrm{~mm} \times 75 \mathrm{~mm}$ window cut-out. This assembly was clamped to the base of the drop-weight tower using four toggle clamps with rubber tips, which prevented slippage of the composite specimen during the impact test [20]. The drop-weight impact experiments were conducted at three energy levels, i.e. $4.5 \mathrm{~J}, 7.5 \mathrm{~J}$ and $10.5 \mathrm{~J}$, and three replicate CF/PEEK and $\mathrm{CF} /$ Epoxy specimens were tested at each energy level. The impact energy was varied by adjusting the height of the impactor. For the impact energies of 4.5, 7.5 and $10.5 \mathrm{~J}$, with the $3.2 \mathrm{~kg}$ impactor, then the corresponding impact velocities were 1.68, 2.16 and $2.56 \mathrm{~m} \mathrm{~s}^{-1}$, respectively. A catching system was used to restrain the impactor at the end of the impact test. A schematic of the experimental set-up for the dropweight impact experiments is shown in Fig. $2 b$. No software filtering of the output load versus time signal was employed and the software for the instrumented drop-weight test provided the impact load and displacement as a function of the timescale of the impact event.

\section{Gas-gun (high-velocity) experiments}

A schematic of the set-up for the gas-gun experiments is given in Fig. 3. In these experiments, the composite specimens were again positioned on a secure platform and fixed by four toggle clamps, as above for the drop-weight experiments, except in this case the fixture was in the vertical plane. For the gasgun system, helium gas was used to feed a four-litre pressure vessel, connected to a three-metre-long barrel by a fast-acting pneumatic value. The velocity of the impactor was controlled by changing the pressure of the vessel and was measured by two pairs of infrared sensors located at the end of the barrel, and this measurement was checked by also using a high-speed camera. The impactors used in the gasgun experiments were machined as bullet-shaped projectiles with a cylindrical main section and a hemispherical nose with a diameter of $12.7 \mathrm{~mm}$, so as to have the same head shape as the impactor used in the drop-weight impact experiments. These impactors were manufactured using 7075-T6 aluminium alloy and had a mass of $7.1 \mathrm{~g}$. For the impact energy of $10.5 \mathrm{~J}$ that was required for the tests, then the corresponding impact velocity was $54.4 \mathrm{~m} \mathrm{~s}^{-1}$. However, it should be noted that for the gas-gun tests it is not possible to predict precisely the exit velocity of the impactor. It was found that, for all the gas-gun tests that were conducted, the velocity of the impactor varied from 53.3 to $55.4 \mathrm{~m} \mathrm{~s}^{-1}$, giving an average impact energy of $10.5 \pm 0.3 \mathrm{~J}$. Two further highspeed cameras were employed for the 3D digital image correlation (DIC) measurements which were focussed on the rear face of the composite specimen onto which an appropriate speckle pattern had been painted. Two light-emitting diode lamps were employed for illuminating the rear face of the specimen for the DIC measurements, and these were only turned on a few seconds before the gas-gun was fired. To measure the full-field deformation of the composite specimens, the image size was selected to be $256 \times 256$ pixels and the frequency of the images taken from the high-speed camera was set as 50,000 frames per second. The DIC experiments provided a full-field out-of-plane displacement history for each test specimen. To check the consistency of the experimental results, two duplicate specimens were tested for each type of composite specimen.

\section{Post-test inspections}

In order to assess the damage suffered by the composite specimens, a visual and an ultrasonic C-scan inspection were carried out. The latter used the 'Prisma' portable C-scan equipment (Sonatest Ltd, UK) and the instrumented probe had a scanning frequency of $5 \mathrm{MHz}$.

\section{Experimental results}

\section{Low-velocity drop-weight impact tests}

\section{Load versus time and load versus displacement results}

Figure 4 shows the results for the measured load as a function of time for the CF/PEEK and CF/Epoxy 


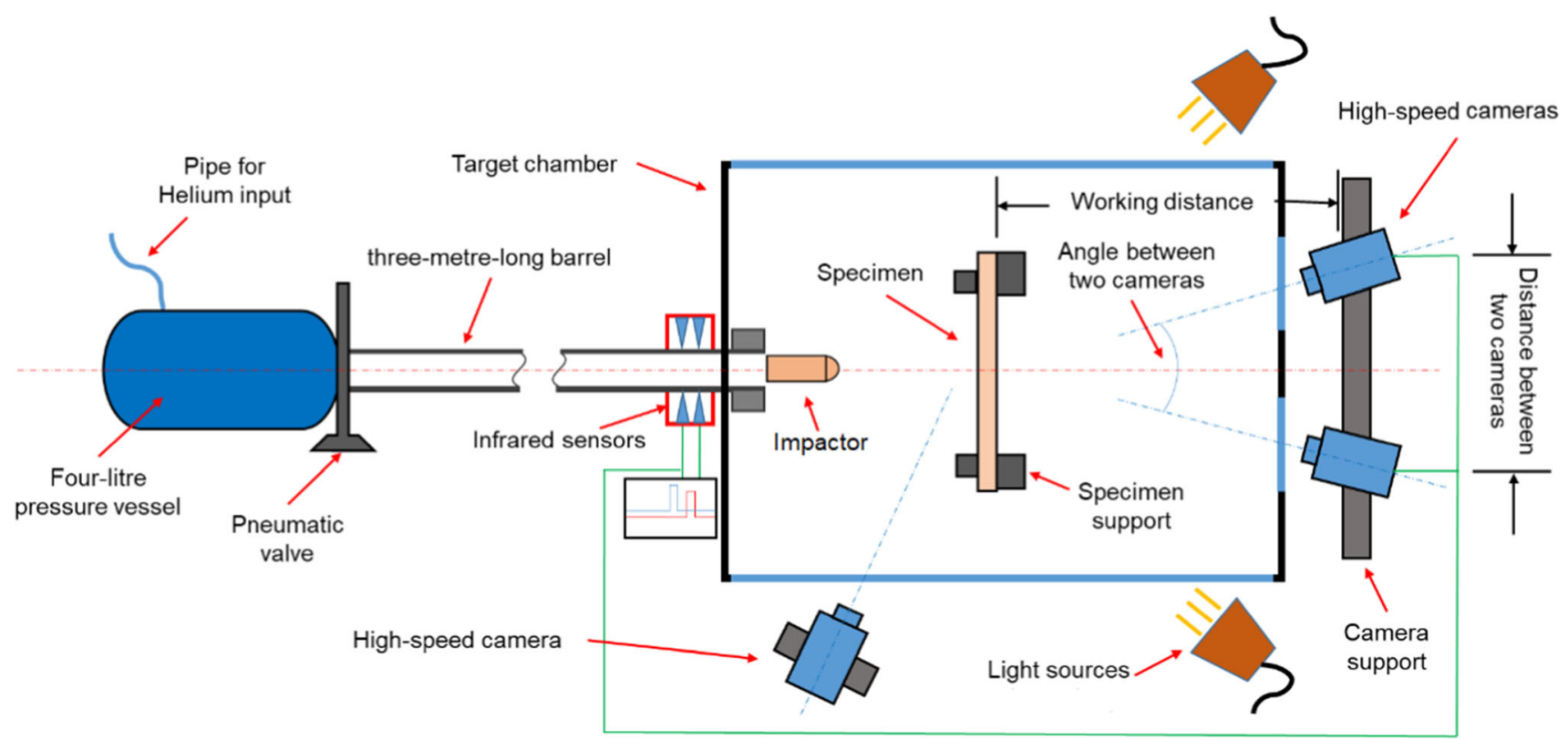

Figure 3 Schematic of the gas-gun test.

composite specimens impacted at energy levels of 4.5, 7.5 and $10.5 \mathrm{~J}$ using the low-velocity drop-weight test. Clearly very good reproducibility is recorded for the three replicate composite specimens. Now, several interesting observations may be made from the results shown in Fig. 4.

Firstly, considering the CF/PEEK composites, Fig. $4 \mathrm{a}$ at an impact energy (IE) $=4.5 \mathrm{~J}$ shows the load versus time curves for the three replicate tests and all these curves reveal that no detectable damage occurred in the CF/PEEK composites, which is confirmed by the C-scan results as discussed below. The relatively small amplitude, sinusoidal oscillations on the rising part of these force versus time curves at an $\mathrm{IE}=4.5 \mathrm{~J}$ are indicative of mass-spring oscillations, as first analysed in detail in [22-24]. However, the load versus time curves shown in Fig. 4a for a higher impact energy of IE $=7.5 \mathrm{~J}$ clearly reveal that the three replicate curves now all exhibit a very major drop in load at $3.4 \pm 4 \% \mathrm{kN}$. This is indicative of the initiation of damage in the composite specimens, as confirmed by the C-scan results below. Likewise, for Fig. $4 \mathrm{a}$ at an IE $=10.5 \mathrm{~J}$, all three replicate curves show a major decrease in load at $3.1 \pm 10 \% \mathrm{kN}$. This again is indicative of damage initiation, as confirmed by the C-scan results shown below.

Secondly, Fig. $4 \mathrm{~b}$ shows that a similar behaviour exists for the CF/Epoxy specimens, but for this composite damage occurs even at the lowest impact energy of $4.5 \mathrm{~J}$. Indeed, the loads at which a major decrease occurs are $2.6 \pm 3 \%, 2.6 \pm 2 \%$ and $2.8 \pm 3 \%$ $\mathrm{kN}$ for the values of impact energy of $4.5,7.5$ and $10.5 \mathrm{~J}$, respectively. These interpretations of the load versus time curves are again confirmed by the $\mathrm{C}$-scan results, as discussed below. Also, as for the CF/PEEK results, at all three impact energy levels there are relatively minor oscillations in the load versus time curves.

Thirdly, Fig. 4c compares a typical load versus time curve for the CF/PEEK composite with one for the CF/Epoxy composite for each impact energy level, and in Table 2, values are given for the average loads for damage initiation and the maximum recorded loads. It is apparent from these results that, at the lowest energy level of $4.5 \mathrm{~J}$, the CF/PEEK composites exhibited a somewhat higher maximum load than that recorded for the CF/Epoxy composites. Further, at this impact energy, whilst damage occurred in the CF/Epoxy composite, no damage was initiated in the CF/PEEK composite specimen and its stiffness at such a relatively high load was therefore not compromised. In contrast, at the highest impact energy of $10.5 \mathrm{~J}$, the results for the CF/PEEK and $\mathrm{CF} /$ Epoxy composites reveal very similar values of the maximum load for both types of composite, although the load for damage initiation is somewhat lower for the CF/Epoxy composite. Indeed, the results show that for the impact energies of both $7.5 \mathrm{~J}$ 
(a)
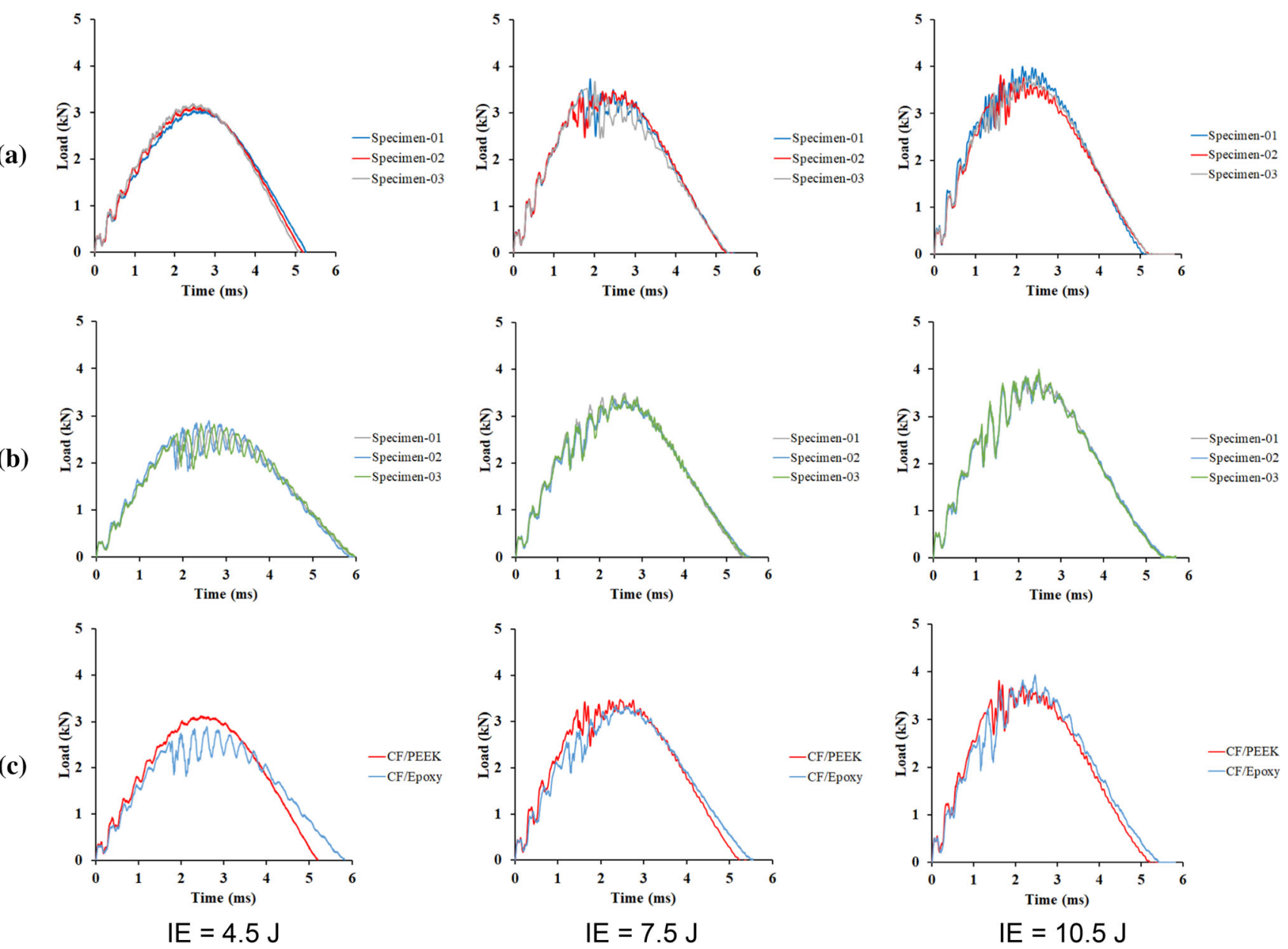

Figure 4 Measured load as a function of time curves for the lowvelocity drop-weight tests at impact energies (IE) of 4.5, 7.5 and $10.5 \mathrm{~J}$ : a CF/PEEK, $\mathbf{b} \mathrm{CF} /$ Epoxy and $\mathbf{c}$ a comparison of typical load versus time curves for the CF/PEEK and CF/Epoxy

composites. (The corresponding impact velocities were 1.68, 2.16 and $2.56 \mathrm{~m} \mathrm{~s}^{-1}$, respectively. The three replicate tests in Fig. 4a, b are labelled 'Specimen-01', 'Specimen-02' and 'Specimen-03'.).

Table 2 Comparison of the measured damage initiation load (i.e. the first major drop in the measured load versus time curve) and the maximum load obtained from the low-velocity drop-weight tests

\begin{tabular}{|c|c|c|c|c|c|c|}
\hline \multirow[t]{2}{*}{ Type of composite } & \multicolumn{3}{|c|}{ Damage initiation load $(\mathrm{kN})$} & \multicolumn{3}{|c|}{ Maximum load $(\mathrm{kN})$} \\
\hline & $4.5 \mathrm{~J}$ & $7.5 \mathrm{~J}$ & $10.5 \mathrm{~J}$ & $4.5 \mathrm{~J}$ & $7.5 \mathrm{~J}$ & $10.5 \mathrm{~J}$ \\
\hline CF/PEEK & - & $3.4 \pm 4 \%$ & $3.1 \pm 10 \%$ & $3.1 \pm 7 \%$ & $3.6 \pm 4 \%$ & $3.9 \pm 3 \%$ \\
\hline CF/Epoxy & $2.6 \pm 3 \%$ & $2.6 \pm 2 \%$ & $2.8 \pm 3 \%$ & $2.8 \pm 6 \%$ & $3.4 \pm 2 \%$ & $3.9 \pm 2 \%$ \\
\hline
\end{tabular}

(Note: there was no evidence of a damage initiation load for the CF/PEEK composite for an impact energy of $4.5 \mathrm{~J}$. The error given is the coefficient of variation from the replicate experiments)

and $10.5 \mathrm{~J}$ the load for damage initiation is consistently somewhat higher for the CF/PEEK than that for the CF/Epoxy composite specimens, but once damage has been initiated and has propagated the general shape of the load versus time curves shown in Fig. 4c for the two types of composite are similar. However, clearly, there are fewer oscillations observed in the load versus time curves for the CF/
PEEK composite as compared with the CF/Epoxy composite, especially at an impact energy of $4.5 \mathrm{~J}$. The reason for this observation is likely to be that the CF/PEEK composite has a better impact resistance than the CF/Epoxy composite. Thus, when subjected to the same impact loading condition, the CF/PEEK composite suffers less damage than the CF/Epoxy composite. As a result, the CF/PEEK composite 
shows relatively fewer oscillations in the load versus time curves compared with the CF/Epoxy composite.

Turning to the load as a function of displacement curves shown in Fig. 5 for the composite specimens impacted at energy levels of $4.5 \mathrm{~J}, 7.5 \mathrm{~J}$ and $10.5 \mathrm{~J}$, then as may be seen the maximum out-of-plane displacement increases with increasing impact energy, as would be expected. No significant difference was found between the values of the maximum displacements undergone by the CF/PEEK and the CF/ Epoxy composite specimens, apart from possibly at the lowest impact energy of $4.5 \mathrm{~J}$ where the CF/ Epoxy test specimen underwent a somewhat higher displacement. This is due to the CF/PEEK composite specimen suffering no damage at all at this lowest impact energy level, unlike the CF/Epoxy composite. Finally, the intersection point between the load versus displacement curve and the $\mathrm{x}$-axis is the out-ofplane displacement corresponding to separation between the impactor and the composite specimen, since for both types of composite the test specimens were never penetrated by the impactor and a significant rebound of the drop-weight impactor occurred at the end of the impact event.

\section{Visual and C-scan inspections}

For all the composite test specimens, no damage could be detected from a simple visual inspection of the specimens after the impact test. However, a slight indentation mark was apparent on the front face of all the test specimens at the impact site.

Figure 6 shows the C-scan damage maps obtained from the composite specimens, impacted at energy levels of 4.5, 7.5 and $10.5 \mathrm{~J}$. At each impact energy, the
Figure 6 C-scan damage maps obtained from the a CF/PEEK and $\mathbf{b} \mathrm{CF} /$ Epoxy replicate composite test specimens impacted at a low-velocity (i.e. the drop-weight test) at impact energies of $4.5 \mathrm{~J}$, $7.5 \mathrm{~J}$ and $10.5 \mathrm{~J}$. The corresponding impact velocities were 1.68, 2.16 and $2.56 \mathrm{~m} \mathrm{~s}^{-1}$, respectively. (The right-hand side scale indicates the location of the interlaminar delamination as a function of the depth through the thickness of the specimen, where the dark red colour represents the front (impacted) face and the dark blue colour represents the rear (non-impacted) face of the composite specimen. The footprint of the damage area detected is given in the top right-hand corner for each specimen and was determined by counting the pixels which had a colour which was not dark blue. The $0^{\circ}$ fibre direction is also indicated.).

three replicate $\mathrm{CF} / \mathrm{PEEK}$ and three replicate $\mathrm{CF} /$ Epoxy composite test specimens were subjected to ultrasonic C-scanning to identify any interlaminar delamination damage that might have resulted. The right-hand side scale in Fig. 6 indicates the location of the delamination damage, as a function of the depth through the thickness of the specimen, where the dark red colour represents the front (impacted) face and the dark blue colour represents the rear (nonimpacted) face of the composite specimen. The areal footprint of the damage detected is given in the top right-hand corner for each specimen and was determined by counting the number of pixels which had a colour which was not dark blue, as the rear surface simply reflects the ultrasound and appears as being dark blue in colour.

In Fig. 6a for the CF/PEEK composites impacted at $4.5 \mathrm{~J}$, it is apparent that there is no delamination damage, as expected from the load versus time curves shown in Fig. 4a. For the CF/PEEK specimens impacted with energies of 7.5 and $10.5 \mathrm{~J}$,

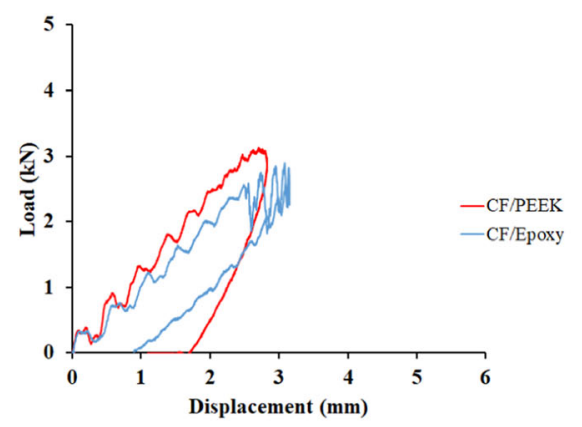

(a)

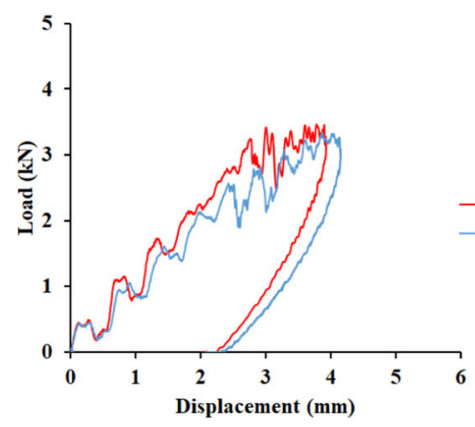

(b)

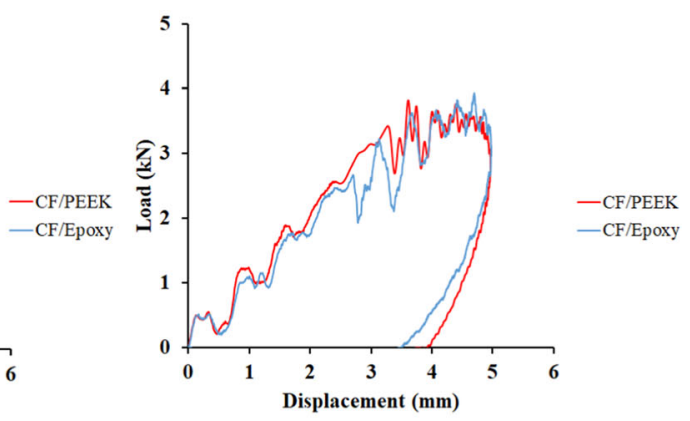

(c)
Figure 5 Measured load as a function of displacement curves for the low-velocity drop-weight tests for the CF/PEEK and CF/Epoxy specimens at impact energies of a $4.5 \mathrm{~J}, \mathbf{b} 7.5 \mathrm{~J}$ and c $10.5 \mathrm{~J}$. (The corresponding impact velocities were $1.68,2.16$ and $2.56 \mathrm{~m} \mathrm{~s}^{-1}$, respectively.). 


\section{CF/PEEK}

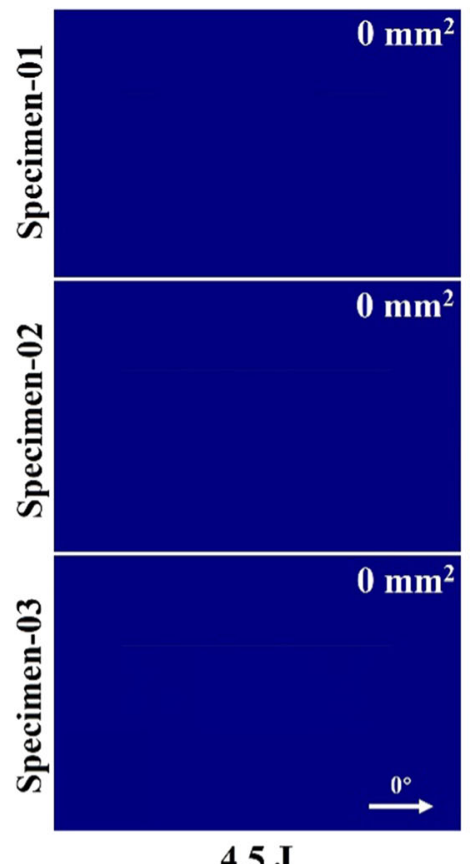

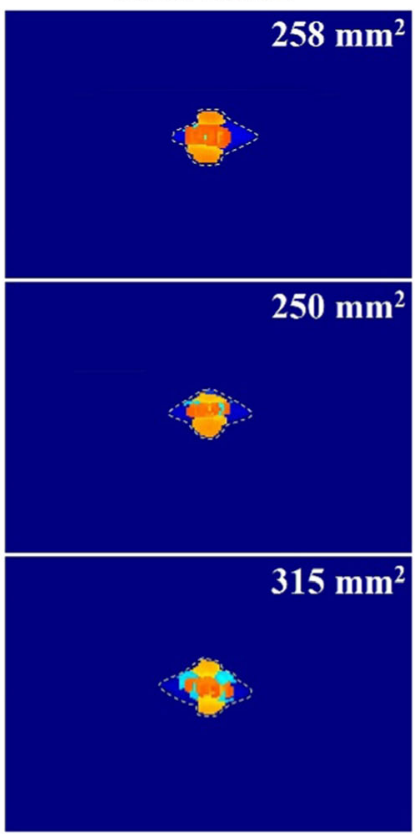

$7.5 \mathrm{~J}$

(a)

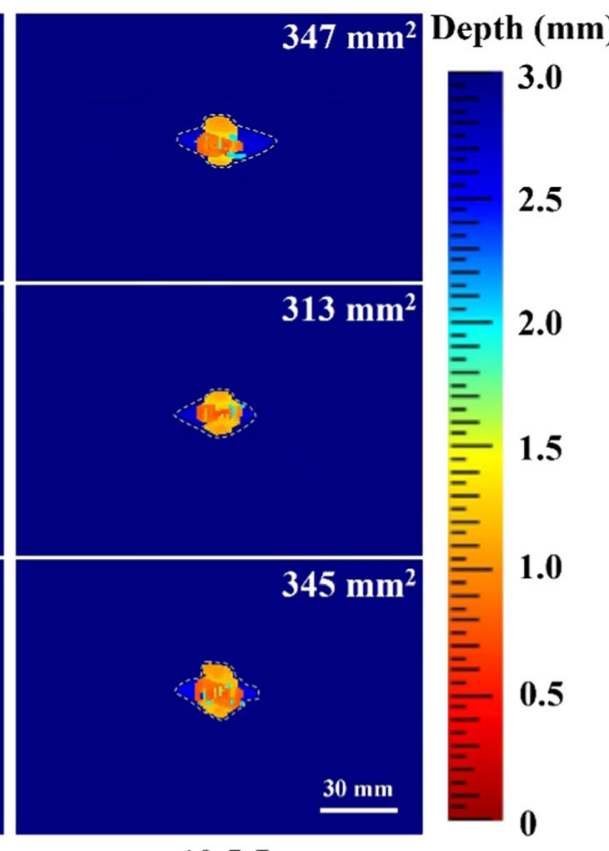

$10.5 \mathrm{~J}$

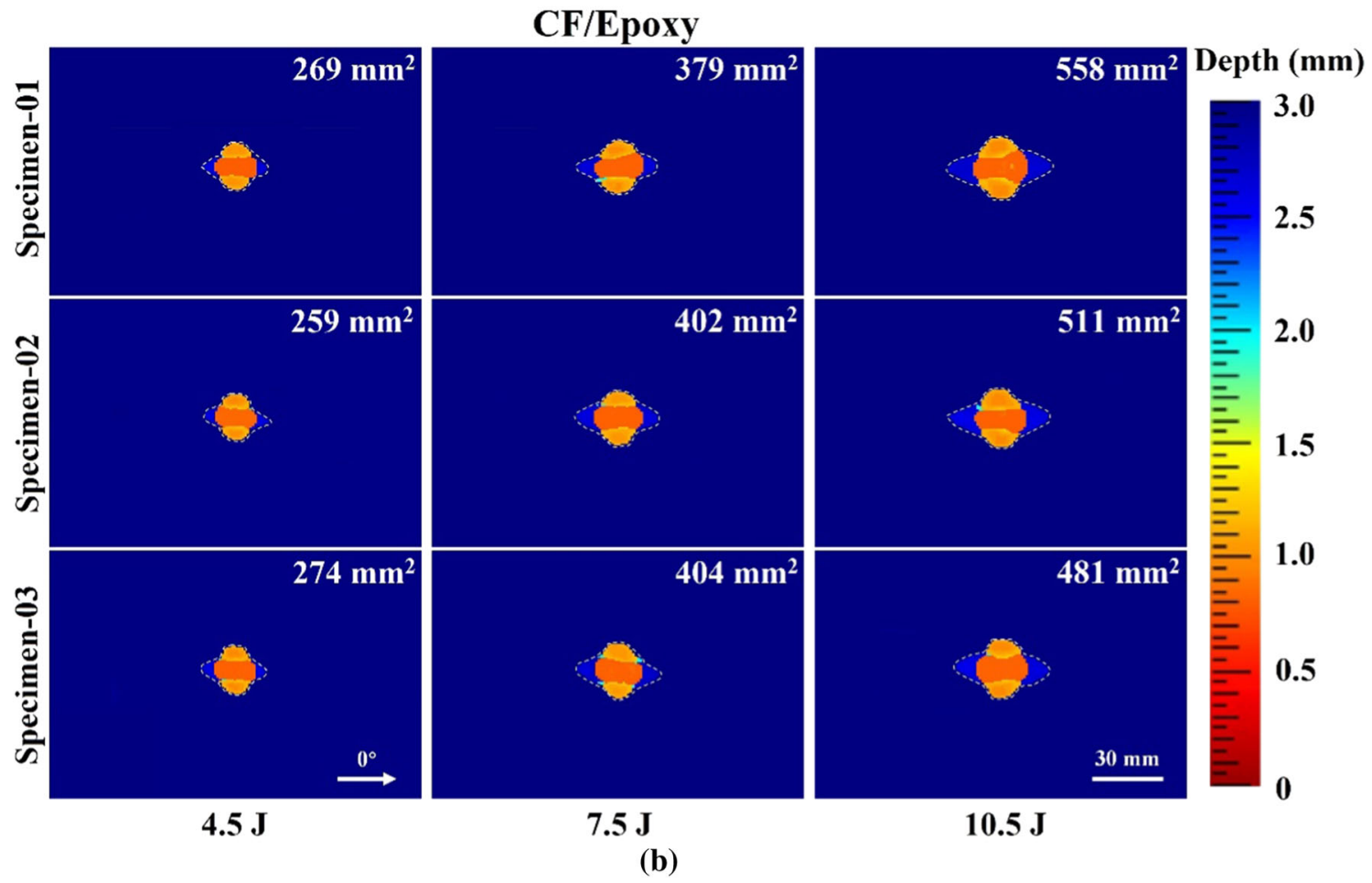


delaminations are detected. Such delamination damage would be expected mainly to occur preferentially between the adjacent $0^{\circ}$ and $90^{\circ}$ ply directions in the $\left[0_{3} / 90_{3}\right]_{2 \mathrm{~s}}$ cross-ply lay-up, since at these interfaces the values of stiffness, in any one direction, of the adjacent ply layers change dramatically from one ply to the next. Thus, the interfacial stresses therefore generated tend to initiate delaminations [13]. Further, the area of the delaminations increases in extent as the impact energy is increased from 7.5 to $10.5 \mathrm{~J}$. In contrast, delaminations are observed to occur in the CF/Epoxy composites at all the impact energies employed and again the damage area steadily increases in size as the impact energy is increased; see Fig. 6b. For both types of composite, which have the same fibre lay-up of $\left[0_{3} / 90_{3}\right]_{2 \mathrm{~s}}$, the delamination damage that is furthest from the impact face is a slightly lighter blue in colour than the background and occurs at a depth of almost $3 \mathrm{~mm}$. This damage is aligned along the longer dimension of the rectangular specimen, consistent with the direction of the $0^{\circ}$ outer ply layer since, in general, delaminations propagate in a direction determined by the orientation of the ply beneath the delamination [13]. The values of the average damage areas, i.e. the area of the delamination footprint, measured from the C-scan maps are summarised in Table 3. This comparison clearly shows that the CF/PEEK composite, when impacted at these relatively low velocities, suffers significantly less damage than the CF/ Epoxy composite when the results are compared at the same energy level.

Table 3 Comparison of the footprint of the damage areas obtained from the low-velocity drop-weight tests as measured from the C-scans

\begin{tabular}{lccc}
\hline Type of composite & \multicolumn{3}{c}{ Average damage area $\left(\mathrm{mm}^{2}\right)$} \\
\cline { 2 - 4 } & $4.5 \mathrm{~J}$ & $7.5 \mathrm{~J}$ & $10.5 \mathrm{~J}$ \\
\hline CF/PEEK & $0 \pm 0 \%$ & $274 \pm 11 \%$ & $335 \pm 5 \%$ \\
CF/Epoxy & $267 \pm 6 \%$ & $395 \pm 3 \%$ & $517 \pm 6 \%$ \\
\hline
\end{tabular}

(The error given is the coefficient of variation from the replicate experiments.)

\section{High-velocity gas-gun impact tests}

\section{Visual and C-scan inspections}

As in the case of the low-velocity drop-weight tests discussed above, for all the composite test specimens no damage could be readily detected from a simple visual inspection of the specimens after being impacted using the gas-gun test. However, a slight indentation mark was apparent on the front face of all the test specimens at the impact site.

Also, as for the low-velocity drop-weight tests, C-scan damage maps were determined for all the composite specimens that had been impacted using the high-velocity gas-gun and it is convenient to first discuss such results. Figure 7 shows C-scan damage maps obtained from the CF/PEEK and CF/Epoxy composite specimens using the gas-gun and impacted at an average high velocity of $54.4 \pm 1.0 \mathrm{~m} \mathrm{~s}^{-1}$, which gives a corresponding average impact energy of $10.5 \pm 0.3 \mathrm{~J}$. Duplicate impact tests were carried out for each type of composite, as shown. The areal footprints of the damage for each test specimen are given in the top right corner of the C-scan maps with the respective impact energy given in the top lefthand corner. These results demonstrate that the CF/ PEEK and CF/Epoxy composites exhibit a similar pattern with values of the average damage area of $1462 \pm 37 \mathrm{~mm}^{2}$ and $1898 \pm 395 \mathrm{~mm}^{2}$, respectively.

\section{Out-of-plane displacement results}

It is difficult to measure the load versus time relationship in a high-velocity gas-gun test and such curves can show considerable dynamic effects, as discussed below when the modelling of such tests is considered. For these reasons, the displacement of the impacted specimen is typically measured. Figure $8 \mathrm{a}$ and $\mathrm{b}$ shows the typical out-of-plane displacement contours obtained from the DIC measurements with respect to the timescale of the impact event for the CF/PEEK and CF/Epoxy test specimens impacted at a velocity of $54.4 \pm 1.0 \mathrm{~m} \mathrm{~s}^{-1}$ and an impact energy of $10.5 \pm 0.3 \mathrm{~J}$. For both composites, it is clear that the deformation is initially localised around the area of the composite specimen that was struck by the impactor. However, as the maximum out-of-plane displacement in the central region of the specimen increases, the deformation then extends elliptically, with the major axis of the 
CF/PEEK

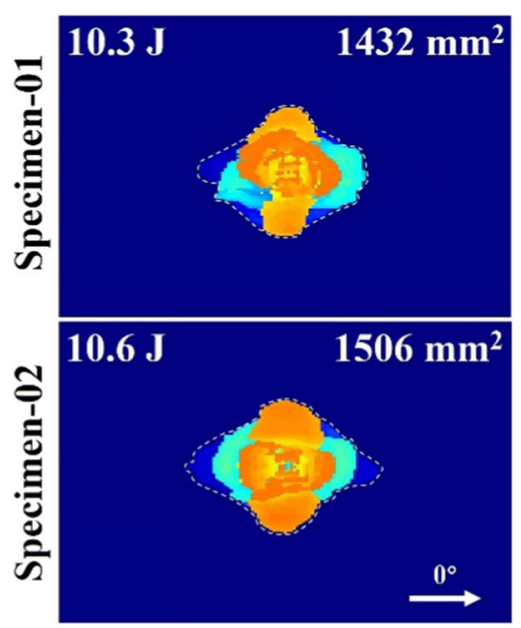

Figure 7 C-scan damage maps obtained from the CF/PEEK and $\mathrm{CF} /$ Epoxy duplicate composite test specimens impacted at a highvelocity (i.e. the gas-gun test). The average impact velocity and energy were $54.4 \pm 1.0 \mathrm{~m} \mathrm{~s}^{-1}$ and $10.5 \pm 0.3 \mathrm{~J}$, respectively.

ellipse aligned with the lengthwise dimension of the specimen, which is the direction of the $0^{\circ}$ plies. For an impact energy of $10.5 \pm 0.3 \mathrm{~J}$, the maximum out-ofplane displacements of the specimens are lower in the case of the high-velocity gas-gun test compared with the low-velocity drop-weight test, as may be seen from comparing Figs. $5 c$ and 8. Indeed, these results reveal that the maximum values from the high-velocity test are approximately $3 \mathrm{~mm}$ for the $\mathrm{CF} / \mathrm{PEEK}$ composite and $3.4 \mathrm{~mm}$ for the CF/Epoxy composite, which may be compared with the values of approximately $5 \mathrm{~mm}$ for both types of composite from the low-velocity tests at an impact energy of $10.5 \mathrm{~J}$. These observations will be discussed later in the context of the modelling studies.

\section{Comparison of damage inflicted by the low- velocity and high-velocity tests}

In Table 4, results are shown comparing the damage areas, as measured from the C-scans, for the CF/ PEEK and CF/Epoxy composite specimens from both the low-velocity (drop-weight) and the high-velocity (gas-gun) tests, but with a similar impact energy of approximately $10.5 \mathrm{~J}$. Firstly, as noted previously, for the low-velocity tests at $2.56 \mathrm{~m} \mathrm{~s}^{-1}$ the CF/Epoxy composites suffer a significantly greater extent of damage than the CF/PEEK composites. Secondly, at the higher test velocity of $54.4 \pm 1.0 \mathrm{~m} \mathrm{~s}^{-1}$ the average damage area for the $\mathrm{CF} /$ Epoxy composites is

\section{CF/Epoxy}

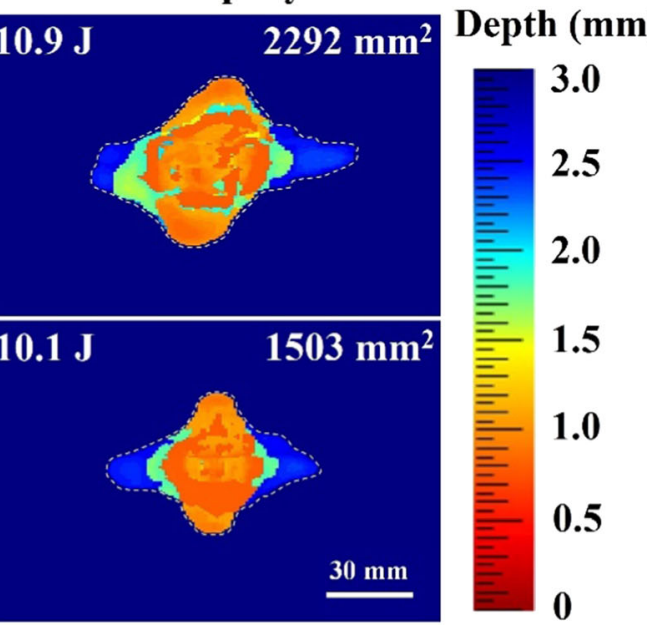

(The actual impact energy for each test is shown in the top lefthand corner for each specimen. See Fig. 6 for the explanation of the experimental $\mathrm{C}$-scan depth scale, etc.).

again greater than for the CF/PEEK composites. Thirdly, both the CF/PEEK and CF/Epoxy composite specimens clearly exhibit very significantly larger damage areas when subjected to the high-velocity tests of approximately $54.4 \pm 1.0 \mathrm{~m} \mathrm{~s}^{-1}$, when compared with the damage areas associated with the lowvelocity tests at $2.56 \mathrm{~m} \mathrm{~s}^{-1}$. This observation undoubtedly arises from several causes, since in the high-velocity tests (a) the CF/PEEK and CF/Epoxy composite specimens have less time to absorb the impact energy, and therefore, the deformation in the specimen is initially more localised around the impact site with an increased curvature of the specimen local to the impact site, which will induce more extensive localised delaminations throughout the composite plies, (b) these extensive localised delaminations will then readily propagate along the various $0^{\circ} / 90^{\circ}$ ply interfaces and (c) the values of the interlaminar and matrix fracture energies will be somewhat lower for both the CF/PEEK and CF/Epoxy composites due to the relatively high strain rate effects associated with the high-velocity test, and therefore, delaminations and matrix damage will initiate and evolve more readily in such high-velocity tests. The overall consequence is that the damage inflicted is more extensive in the high-velocity tests compared with the low-velocity tests, as indeed is observed from the greater area of delaminations in the C-scans of the high-velocity tests; see Figs. 6 and 7 , and Table 4. 

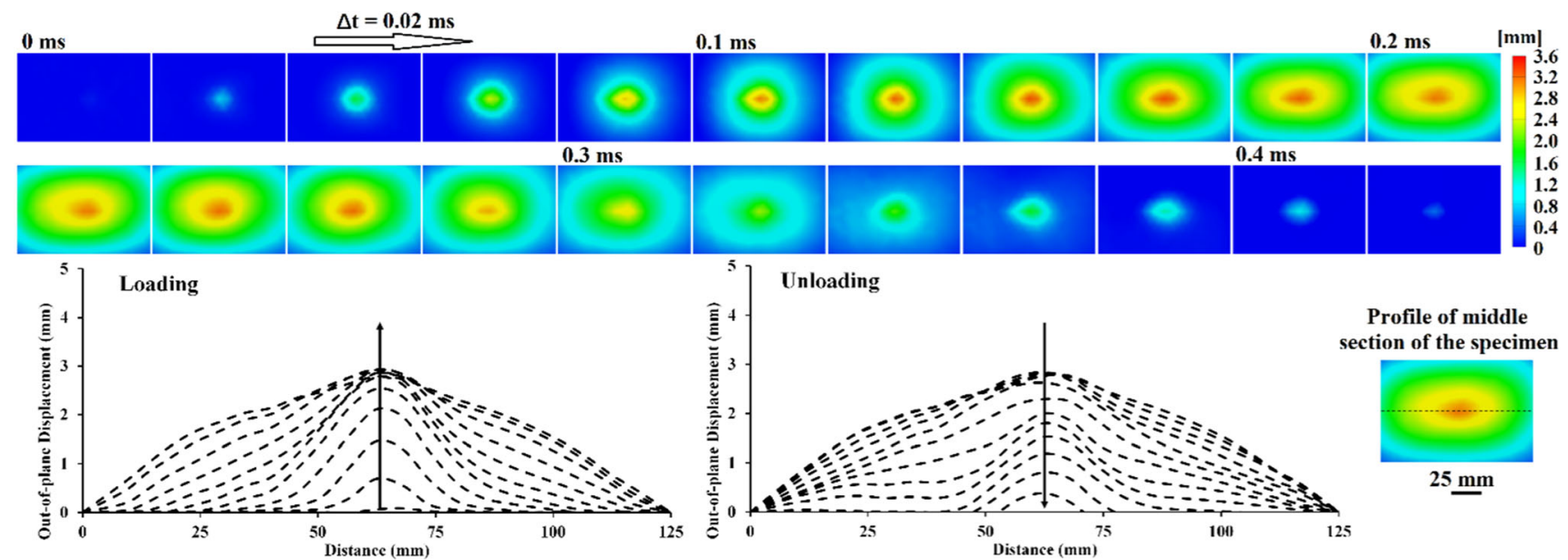

Profile of middle ection of the specimen

(a)
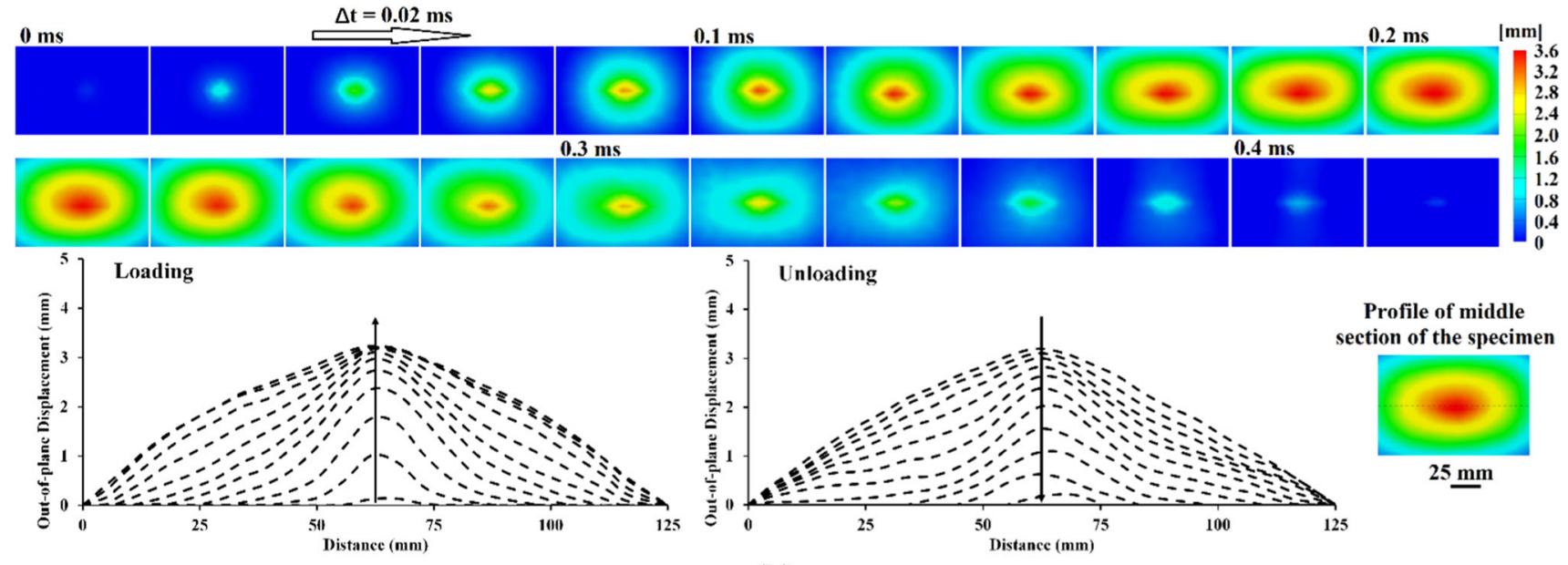

Profile of middle section of the specimen

(b)

Figure 8 Maps and diagrams of the typical full-field out-of-plane displacements of the rear surface of the composite specimens measured for both the loading (upper map strips) and unloading (lower map strips) phases for the high-velocity gas-gun experiments at $54.4 \pm 1.0 \mathrm{~m} \mathrm{~s}^{-1}$ and an impact energy of $10.5 \pm 0.3 \mathrm{~J}$ for the: $\mathbf{a} \mathrm{CF} / \mathrm{PEEK}$ and $\mathbf{b} \mathrm{CF} /$ Epoxy composite test specimens. (For the displacement maps the value of the

\section{Comparison of the impact behaviour of the CF/PEEK and CF/Epoxy composites}

In the low-velocity impact experiments, the CF/ PEEK and CF/Epoxy composites both showed an increase in the maximum load as the impact energy level is increased, as shown in Figs. 4 and 5, and Table 2. Also, the impact duration time for the CF/ Epoxy composite was marginally greater than that for the CF/PEEK composite, with the difference between the duration time for the CF/PEEK and CF/ Epoxy composites showing a reduction with displacement is given by the scale bar, with the brightest red colour representing in the range of about 3.2 to $3.6 \mathrm{~mm}$. For the out-ofplane displacement diagrams, the time interval between the dashed lines is $0.02 \mathrm{~ms}$. The diagrams give the displacement values taken across the middle section of the specimen, as illustrated schematically in the scaled map to their right.).

increasing impact energy. A similar trend was also observed for the values of the displacements of the $\mathrm{CF} / \mathrm{PEEK}$ and CF/Epoxy composite specimens, as shown in Fig. 5. In general, the loading responses measured for the CF/PEEK composite showed less oscillations compared with those observed for the CF/Epoxy composite, as discussed above. Also, of course, at a given level of impact energy, the CF/ PEEK composites suffered significantly less damage compared with the CF/Epoxy composites, as may be seen from the results shown in Fig. 6 and Table 4. 
Table 4 Comparison of the footprint of the damage areas as measured from the C-scans obtained from the low-velocity dropweight and high-velocity gas-gun tests at a similar impact energy of $10.5 \pm 0.3 \mathrm{~J}$

\begin{tabular}{lll}
\hline Type of composite & \multicolumn{2}{l}{ Average damage area $\left(\mathrm{mm}^{2}\right)$} \\
\cline { 2 - 3 } & At $2.56 \mathrm{~m} \mathrm{~s}^{-1}$ & At $54.4 \pm 1.0 \mathrm{~m} \mathrm{~s}^{-1}$ \\
\hline CF/PEEK & $335 \pm 5 \%$ & $1462 \pm 3 \%$ \\
CF/Epoxy & $517 \pm 6 \%$ & $1898 \pm 21 \%$ \\
\hline
\end{tabular}

(The error given is the coefficient of variation from the replicate experiments.)

In the high-velocity impact experiments, both the CF/PEEK and CF/Epoxy composite specimens exhibited a relatively larger damage area than when tested in the low-velocity impact experiments, using the same impact energy level of $10.5 \pm 0.3 \mathrm{~J}$; see Figs. 6 and 7, and Table 4. This implies an effect of the strain rate of the test. It was also found that the area of the damage footprint in the CF/PEEK composites showed a larger percentage increase upon going from the low-velocity impact to the high-velocity impact test than that observed for the $\mathrm{CF}$ / Epoxy composite. Also, the DIC results obtained for the CF/PEEK and CF/Epoxy composites for the high-velocity test revealed that the CF/Epoxy composite underwent a marginally higher out-of-plane displacement than that of the CF/PEEK composite; see Fig. 8.

It is of interest to compare the above experimental results with those previously reported in the literature. Firstly, in the present work, when a higher impact energy is employed in the low-velocity impact tests, both the CF/PEEK and CF/Epoxy composites tend to undergo a somewhat greater maximum load, larger displacement and exhibit more severe impactinduced damage; see Figs. 4, 5 and 6. Similar observations have been previously reported by Dorey et al. [3] and Vieille et al. [12]. Secondly, in the present research, for both the low- and high-velocity impact tests, the CF/PEEK composite exhibited a superior impact performance compared with the CF/Epoxy composite, e.g. the CF/PEEK composite suffered less impact-induced damage. Similar results have also been also reported, for example, in [3, 15]. However, on the other hand, some other researchers [18, 19] have found that the impact performance of thermoplastic matrix composites is not always superior to those of thermoset matrix composites, as discussed above in detail. Thirdly, in the present work, strain rate effects were observed for both the CF/PEEK and $\mathrm{CF} /$ Epoxy composites. This may be readily observed from the fact that in the present work, when the impact energy employed in both the low- and highvelocity impact tests was $10.5 \pm 0.3 \mathrm{~J}$, both the CF/ PEEK and the CF/Epoxy composites suffered significantly greater impact damage from the high-velocity impact tests (at $54.4 \mathrm{~m} \mathrm{~s}^{-1}$ ) than from the lowvelocity tests (at $2.56 \mathrm{~m} . \mathrm{s}^{-1}$ ); see Figs. 6 and 7, and Table 4. Similar results have been observed by Cantwell and Morton [6]. Fourthly, it was also found that the CF/PEEK composites were more sensitive to such strain rate effects, since a relatively higher extent of damage area was observed in the CF/PEEK composite, compared with the CF/Epoxy composite, when the impact velocity was significantly increased at the same impact energy of $10.5 \pm 0.3 \mathrm{~J}$; again see Figs. 6 and 7, and Table 4. Other researchers, such as Morita et al. [18], have also observed similar effects when the impact velocity is significantly increased.

\section{The composite damage model}

\section{Brief overview of the damage model}

It is obviously of great interest to attempt to model the experimental result from the impact tests described above and, once validated, to use the model to carry out predictive studies. The impact event for the relatively hard impactor striking the CFRP composite specimen was therefore modelled using the 'Abaqus/Explicit 2018' finite element (FE) code [25]. An overall flow chart of the basic two-dimensional, elastic, FE methodology is shown in Fig. 9, and the model is shown schematically in Fig. 10. The impactor was modelled as a spherically shaped, rigid surface, with a reference lumped mass of $3.2 \mathrm{~kg}$ or $7.1 \mathrm{~g}$ for the low- and high-velocity tests, respectively. The composite specimen was defined using continuum shell elements, and thus, only the in-plane material properties are required for the numerical modelling. The elements had a size of $1 \mathrm{~mm} \times 1 \mathrm{~mm}$, and this mesh size was found to give mesh-independent results. Cohesive surfaces were defined at the $0^{\circ} / 90^{\circ}$ interfaces to capture the interlaminar damage. A general contact algorithm was employed to govern the global contact, and the friction coefficients for the 


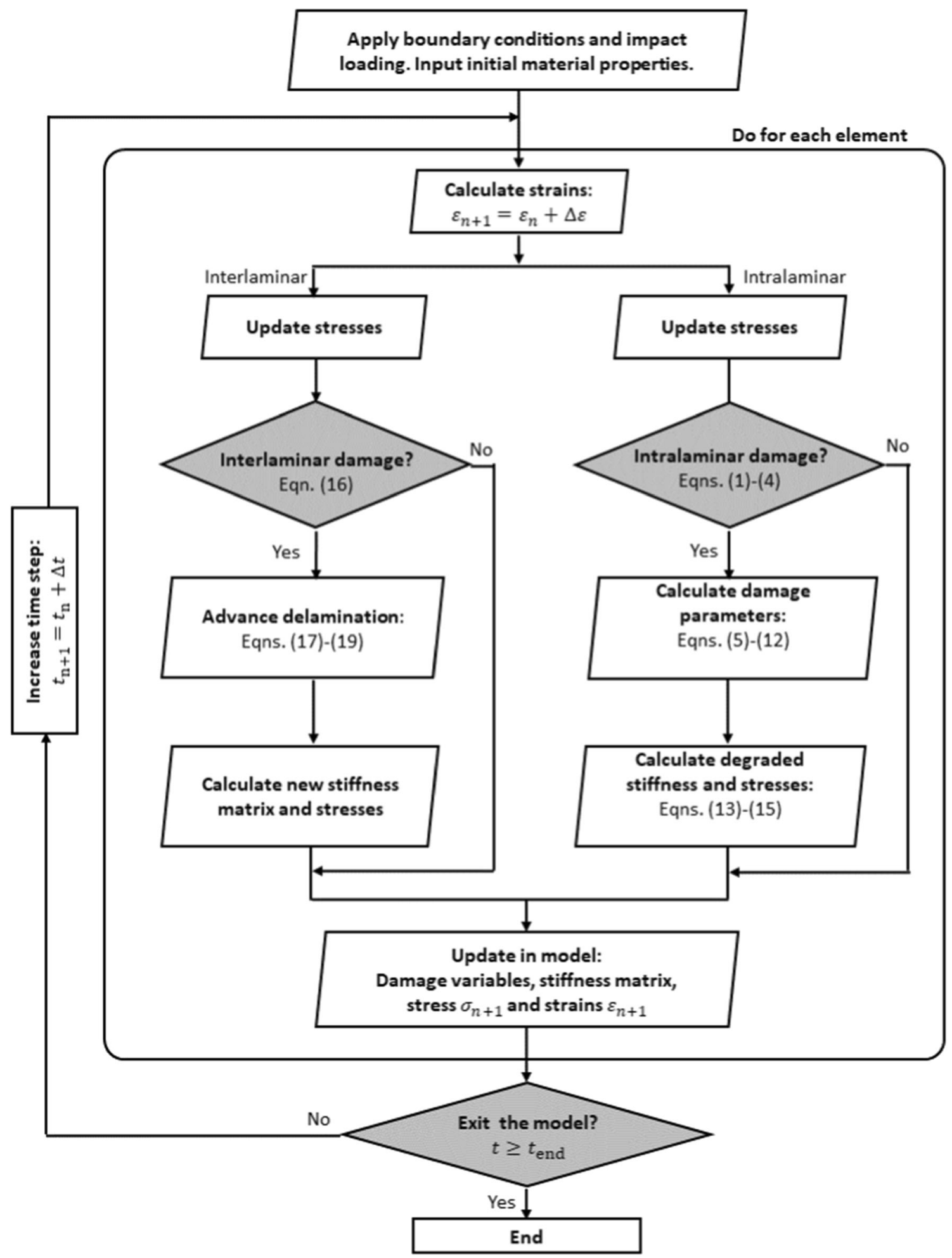

Figure 9 Implementation of the FE model showing schematically the flow chart, for one computation time step, for a single element for modelling the interlaminar and intralaminar damage.

metal/composite ply and composite ply/composite ply interfaces were set as 0.2 and 0.25 , respectively $[26,27]$. The computational accuracy was set as 'double procession' to reduce the accumulation of error during the simulation. The FE model for the low-velocity drop-weight test was typically run as 


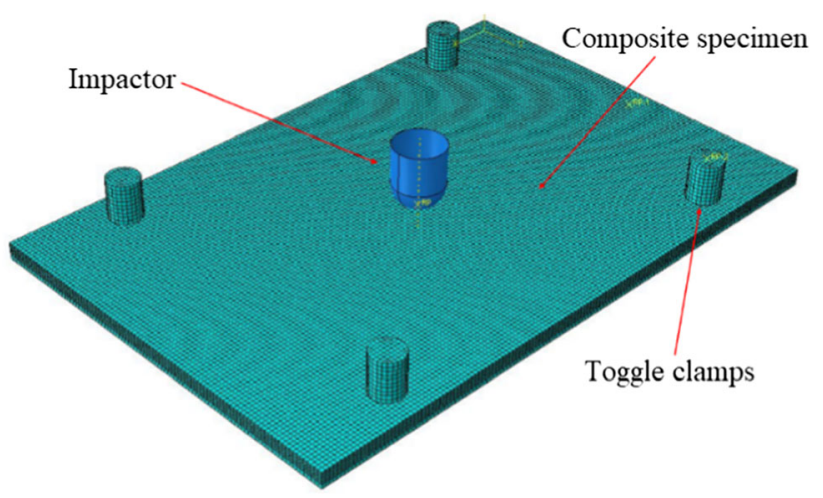

Figure 10 Schematic of the FE model.

individual time steps, $\Delta t$, of $0.06 \mathrm{~ms}$ for about 100 steps, which represents the order of the experimentally measured time of about $6 \mathrm{~ms}$ for the complete impact event to take place. For the high-velocity gasgun test, the model was typically run as individual time steps, $\Delta t$, of $0.005 \mathrm{~ms}$ for about 100 steps, which represents the order of the experimentally measured time of about $0.5 \mathrm{~ms}$ for the complete impact event to take place. A computational time step was performed for every appropriate single element in the FE model. The modelling runs were stopped when the defined total time for the impact event had expired. Computations were performed using 32 CPUs on a 'Linux Cluster' with a run time of $12-15 \mathrm{~h}$. The material coordinate system for the CFRP laminate was defined with the lengthwise direction of the specimen being the 11-direction and the widthwise direction being the 22-direction. For the $0^{\circ}$ plies, the fibre direction was aligned with the 11-direction, and for the $90^{\circ}$ plies, the fibres were aligned in the 22-direction.

\section{The intralaminar damage model}

\section{Initiation of intralaminar damage}

The model for predicting the initiation of any intralaminar damage was based upon Hashin's 2-D theory $[28,29]$ which assumes that the undamaged composite exhibits linear elastic behaviour. In Hashin's damage model, four different types of damage mechanisms, which arise from tensile fibre failure, compressive fibre failure, tensile matrix failure and compressive matrix failure, are employed to capture the initiation of intralaminar damage in the unidirectional fibre sub-plies. The general forms of the damage criteria in Hashin's approach to model the initiation of these four different types of damage are given by:

For tensile fibre failure $\left(\hat{\sigma}_{11} \geq 0\right): F_{f}^{t}$

$$
=\left(\frac{\hat{\sigma}_{11}}{X^{T}}\right)^{2}+\left(\frac{\hat{\tau}_{12}}{S^{L}}\right)^{2}
$$

For compressive fibre failure $\left(\hat{\sigma}_{11}<0\right): F_{f}^{c}=\left(\frac{\hat{\sigma}_{11}}{X^{\mathrm{C}}}\right)^{2}$

For tensile matrix failure $\left(\hat{\sigma}_{22} \geq 0\right): F_{m}^{t}$

$$
=\left(\frac{\hat{\sigma}_{22}}{Y^{T}}\right)^{2}+\left(\frac{\hat{\tau}_{12}}{S^{L}}\right)^{2}
$$

For compressive matrix failure $\left(\hat{\sigma}_{22}<0\right): F_{m}^{c}$

$$
=\left(\frac{\hat{\sigma}_{22}}{2 S^{T}}\right)^{2}+\left[\left(\frac{Y^{C}}{2 S^{T}}\right)^{2}-1\right] \frac{\hat{\sigma}_{22}}{Y^{C}}+\left(\frac{\hat{\tau}_{12}}{S^{L}}\right)^{2}
$$

In the above equations, the indices on the terms $F_{f}^{t}$, $F_{f}^{c}, F_{m}^{t}$ and $F_{m}^{c}$ represent the four types of damage of tensile fibre failure, compressive fibre failure, tensile matrix failure and compressive matrix failure, respectively, and failure is predicted to occur when $F \geq 1$. The parameters $X^{T}$ and $X^{C}$ denote the tensile and compressive strengths of the laminate in the longitudinal fibre direction, respectively. The terms $Y^{T}$ and $Y^{C}$ are the tensile and compressive strengths of the laminate in the transverse direction, respectively; $S^{L}$ and $S^{T}=Y^{C} / 2$ denote the shear strengths of the laminate in the longitudinal and transverse directions to the fibres, respectively; and the terms $\hat{\sigma}_{11}, \hat{\sigma}_{22}$ and $\hat{\tau}_{12}$ are the normal and shear components of the effective stress tensor, $\hat{\sigma}$, that are used to evaluate the above criteria.

\section{The evolution of intralaminar damage}

Corresponding to the damage initiation criteria defined in Hashin's theory, Eqs. 1-4, four damage variables, $d_{f}^{t}, d_{f}^{c}, d_{m}^{t}$ and $d_{m}^{c}$, were implemented in the damage evolution model, which arise from tensile fibre failure, compressive fibre failure, tensile matrix failure and compressive matrix failure, respectively. These damage variables have the value of 0 when the element is undamaged and 1 when fully damaged. A general form of the damage variable, $d$, once a particular damage mechanism initiates, is given by [25]: 
$d=\frac{\varepsilon f\left(\varepsilon-\varepsilon^{0}\right)}{\varepsilon\left(\varepsilon^{f}-\varepsilon^{0}\right)}$

where the strain, $\varepsilon$, is the applied strain and the strain values $\varepsilon^{0}$ and $\varepsilon^{f}$ are those corresponding to the initiation of damage and final failure, respectively. For tensile fibre or compressive fibre failure, the terms $\varepsilon$, $\varepsilon^{0}$ and $\varepsilon^{f}$ are assigned to be $\varepsilon=\varepsilon_{11}, \varepsilon^{0}=\varepsilon_{11}^{0}$ and $\varepsilon^{f}=\varepsilon_{11}^{f}$, respectively, with the second superscripts of $t$ or $c$ being used to indicate tensile or compressive stresses, respectively. Similarly, for tensile or compressive matrix failure, the terms $\varepsilon, \varepsilon^{0}$ and $\varepsilon^{f}$ are assigned to be $\varepsilon=\varepsilon_{22}, \varepsilon^{0}=\varepsilon_{22}^{0}$ and $\varepsilon^{f}=\varepsilon_{22}^{f}$, respectively, with the second superscripts of $t$ or $c$ being used to indicate tensile or compressive stresses, respectively.

Now, the applied strain, $\varepsilon$, may be deduced from interrogating the FE output for any element for a given time step. In the damage evolution model, the values of the initial failure strains, $\varepsilon^{0}$, are equal to the strain values corresponding to damage initiation, which may be directly obtained from the computation via implementing Eqs. 1-4. The final failure strains, $\varepsilon^{f}$, are given by [30]:

For tensile fibre failure : $\varepsilon_{11}^{f t}=\left.2 G_{I c}\right|_{f t} /\left(X^{T} l_{c}\right)$

For compressive fibre failure : $\varepsilon_{11}^{f c}=\left.2 G_{I c}\right|_{f c} /\left(X^{C} l_{c}\right)$

For tensile matrix failure : $\varepsilon_{22}^{f t}=\left.2 G_{I c}\right|_{m t} /\left(Y^{T} l_{c}\right)$

For compressive matrix failure : $\varepsilon_{22}^{f c}=\left.2 G_{I c}\right|_{m c} /\left(Y^{C} l_{c}\right)$

where the terms $\left.G_{I c}\right|_{f t}$ and $\left.G_{I c}\right|_{f c}$ are the tensile and compressive intralaminar ply fracture energies in the longitudinal fibre direction, and $\left.G_{I c}\right|_{m t}$ and $\left.G_{I c}\right|_{m c}$ are the tensile and compressive interlaminar ply fracture energies in the transverse to the fibre direction. The characteristic length, $l_{c}$, is equal to the edge length of the element.

Three damage parameters, $d_{f}, d_{m}$ and $d_{s}$, which reflect fibre damage, matrix damage and shear damage, respectively, may then be derived from these damage variables, $d_{f}^{t}, d_{f}^{c}, d_{m}^{t}$ and $d_{m}^{c}$, as follows [25]:
For fibre damage $: d_{f}=\left\{\begin{array}{l}d_{f}^{t}, \hat{\sigma}_{11} \geq 0 \\ d_{f}^{c}, \hat{\sigma}_{11}<0\end{array}\right.$

For matrix damage $: d_{m}=\left\{\begin{array}{l}d_{m}^{t}, \hat{\sigma}_{22} \geq 0 \\ d_{m}^{c}, \hat{\sigma}_{22}<0\end{array}\right.$

For shear damage : $d_{s}=1-\left(1-d_{f}^{t}\right)\left(1-d_{f}^{c}\right)$

$$
\left(1-d_{m}^{t}\right)\left(1-d_{m}^{c}\right)
$$

Now, prior to damage initiation the composite laminate is taken to be linear elastic, with the stiffness matrix of a plane stress orthotropic material. Once the damage initiates and starts to evolve, the response of the material is computed from:

$\sigma=C_{d} \varepsilon$

where $C_{d}$ is the damaged elasticity matrix, which has the form [25]:

$C_{d}=\frac{1}{D}\left[\begin{array}{ccc}\left(1-d_{f}\right) E_{11} & \left(1-d_{f}\right)\left(1-d_{m}\right) v_{21} E_{11} & 0 \\ \left(1-d_{f}\right)\left(1-d_{m}\right) v_{12} E_{22} & \left(1-d_{m}\right) E_{22} & 0 \\ 0 & 0 & \left(1-d_{s}\right) G_{12} D\end{array}\right]$

where $D=1-\left(1-d_{f}\right)\left(1-d_{m}\right) v_{12} v_{21}, E_{i i}(i=1,2)$ is the elastic modulus in the longitudinal or transverse directions, $G_{12}$ is the shear modulus and $v_{i j}(i, j=1,2 i \neq j)$ are the Poisson's ratios. Now, the values of the damage variables, $d_{f}, d_{m}$ and $d_{s}$, reflect the current state of fibre damage, matrix damage and shear damage, respectively, and may be calculated from Eqs. 10 to 12. Thus, the degraded stresses acting in any element for any time step for an applied strain, $\varepsilon$, can now be computed from Eqs. 13 to 14. These degraded stresses and strains may then be updated, as being the 'new model state', for a given element in the next time step of the run of the FE model; see Fig. 9. For the simulations of the extent of intralaminar damage as a function of the timescale of the impact event that are deduced from the model then, following earlier work [31], a value for the damage parameter of equal to, or greater, than 0.9 is used to define the relatively intense intralaminar damage, i.e. to calculate the areas indicated by the red colour in the figure shown later.

From the above discussions, it is evident that if any of the four intralaminar damage mechanisms have been activated as determined from the Hashin criteria, see Eqs. 1-4, then the elastic properties in those elements in the FE model will start to degrade, as defined above in Eq. 14, which is based upon the 
damage parameters calculated in Eqs. 6 to 12. Finally, when any of these three damage parameters meet the condition, as stated in Eq. (15) below, then these damaged elements are deleted from the model [25]:

Delete element if : $\left\{\begin{array}{l}d_{f}>0.99 \\ d_{m}>0.99 \\ d_{s}>0.99\end{array}\right.$

\section{The interlaminar damage model}

Interlaminar damage typically involves the initiation and growth of delamination between the plies that make up the composite laminate and this was captured using the Abaqus built-in surface-based cohesive (i.e. interface) element using an energy release approach [25]. The interface element was described via a cohesive (i.e. damage) surface law [32-36] where the traction, $\sigma$, is a function of the displacement, $\delta$, as shown schematically in Fig. 11, and is in the form of a bilinear cohesive law for a linear softening material model. This damage law is divided into two steps. Before the initiation of any delamination, the relationship possesses linear elastic behaviour. Once the damage criterion is satisfied, at a value of the displacement of $\delta^{o}$, the cohesive stiffness degrades linearly until separation of the interface, i.e. the delamination now propagates when the maximum failure displacement of $\delta^{f}$ is attained. The energy under the bilinear cohesive law is equivalent to the interlaminar fracture energy, $G_{c}$, and the evaluation of this term, and of the initial stiffness, $k$, of the interface element, is discussed below. Finally, the initiation and growth of any intralaminar damage, as discussed above, significantly influence the extent of interlaminar damage, and hence, these two

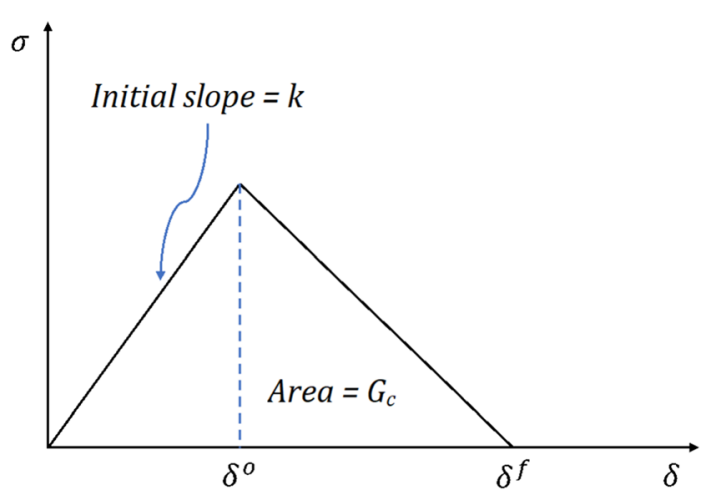

Figure 11 Schematic of the bilinear cohesive surface law. damage modes were modelled to be interactive in the Abaqus simulation; see Fig. 9.

\section{The initiation of interlaminar damage}

To analyse the interlaminar damage, a quadratic stress criterion was employed, which determines the initiation of any interlaminar damage in the composite laminates. This was implemented within the FEA code and the criterion is given by $[25,37]$ when:

$\left(\frac{\left\langle\sigma_{n}\right\rangle}{\sigma_{n}^{0}}\right)^{2}+\left(\frac{\tau_{s}}{\tau_{s}^{0}}\right)^{2}+\left(\frac{\tau_{t}}{\tau_{t}^{0}}\right)^{2}=1$

where $\sigma_{n}$ represents the current stress that is acting normal to the ply, and $\tau_{s}$ and $\tau_{t}$ represent the current shear stresses that are acting on the ply. The values of the cohesive strengths, $\sigma_{n}^{0}, \tau_{s}^{0}$ and $\tau_{t}^{0}$, denote the interface tensile and shear strengths, respectively. Employing the quadratic stress criterion, the value of the damage initiation displacement, $\delta^{o}$, see Fig. 11, may be calculated.

\section{The evolution of interlaminar damage}

The embedded cohesive surface law, see Fig. 11, requires a value of the interlaminar fracture energy, $G_{c}$, and this represents the area under the bilinear law. The energy-based Benzeggagh-Kenane (B-K) $[25,38,39]$ mixed-mode propagation criterion was used to derive a value $G_{c}$ for the growth of the delamination between the composite plies, as given by:

$G_{c}=G_{I c}+\left(G_{I I c}-G_{I c}\right)\left(\frac{G_{I I}}{G_{I}+G_{I I}}\right)^{\eta}$

where $G_{I c}$ is Mode I (opening tensile) interlaminar facture energy, $G_{I I c}$ is Mode II (in-plane shear) interlaminar facture energy and $\eta$ is the B-K mixed-mode interaction exponent. The values of all these terms may be experimentally measured [38-41]. The parameters $G_{I}$ and $G_{I I}$ are the current Mode I and Mode II energy release rates, respectively, as calculated from the FE code by multiplying the relevant local stress by its conjugate displacement. The stiffness, $k$, of the cohesive law is given by [36]:

$k=\frac{\alpha E_{22}}{t_{e}}$

where $\alpha$ is a constant much larger than unity, i.e. $\alpha \gg 1$, and $t_{e}$ is the thickness of an adjacent ply. From 
the known values of $k, \delta^{o}$ and $G_{c}$ the cohesive surface law, as shown in Fig. 11, may now be completely and quantitatively described. Finally, complete fracture of the interface element is assumed to occur, and delamination (i.e. interlaminar cracking) results, when the cohesive traction vanishes at the end of the degradation step. That is when the displacement, $\delta$, of the interface element, as determined in the FE code, attains the criterion:

$\delta=\delta^{f}$

where $\delta^{f}$ is the displacement of the element at failure; see Fig. 11. For the simulations of the location and extent of interlaminar delamination as a function of the impact velocity and energy, and the timescale of the impact event, that are deduced from the model then, following earlier work [31], a value corresponding to the displacement ratio of $\delta / \delta^{f}$ of equal to, or greater, than 0.9 is used, i.e. to calculate the areas shown by the red colour in the figures shown later.

\section{Results from the modelling studies}

\section{Material properties}

The material properties of the CF/PEEK and CF/ Epoxy composites required for the FE modelling studies are given in Table 5 . These properties were typically measured at strain rates in the range of $10^{-3}$ to $10^{0} \mathrm{~s}^{-1}$.

\section{Simulations of the low-velocity drop-weight impact test results}

As for the experimental tests, simulations were carried out at three different energy levels of 4.5, 7.5 and $10.5 \mathrm{~J}$, which correspond to impact velocities of 1.68 , 2.16 and $2.56 \mathrm{~m} \mathrm{~s}^{-1}$ respectively. The strain rate for the composite test specimens for the low-velocity drop-weight tests is about $3 \mathrm{~s}^{-1}$ for an impact velocity of $2.56 \mathrm{~m} \mathrm{~s}^{-1}$. It was considered that this relatively low value of strain rate would not lead to significantly different values of the material properties to those shown in Table 5 and these properties were therefore used in the FE modelling studies for the low-velocity impact tests.

The predicted damage maps from the modelling studies for the three different impact energies are compared with the corresponding experimental results in Figs. 12 and 13 for the CF/PEEK and CF/ Epoxy composites, respectively. (To enable a ready comparison between the footprints of the delamination areas obtained from the experiments and the simulation, the predicted damage maps show the overall area of the damage footprint, which encompasses the contours of all the interlaminar delamination areas that are predicted to occur at various depths in the through-thickness direction. Further, the values of the delamination areas stated on the experimentally measured damage maps represent the mean value of the areas that were measured from the replicate tests; see Fig. 6.) As may be seen, for both types of composite the predicted damage area increases with impact energy and such increases are

Table 5 Input properties for the FE modelling studies of the CF/PEEK [17] and CF/Epoxy [17, 42] composites

\begin{tabular}{lll}
\hline Property & Unidirectional CF/PEEK ply & Unidirectional CF/Epoxy ply \\
\hline Moduli (GPa) & $E_{11}=127 ; E_{22}=10.3 ; G_{12}=5.7$ & $E_{11}=130 ; E_{22}=7.7 ; G_{12}=4.8$ \\
Poisson's ratio & $v_{12}=0.3$ & $v_{12}=0.3$ \\
Strength values (MPa) & $X^{T}=2070 ; Y^{T}=85 ;$ & $X^{T}=1950 ; Y^{T}=75$ \\
& $X^{C}=1360 ; Y^{C}=276$ & $X^{C}=1015 ; Y^{C}=220$ \\
& $S^{L}=186$ & $S^{L}=150$ \\
Ply fracture & $\left.G_{I c}\right|_{f t}=218 ;\left.G_{I c}\right|_{f c}=104$ & $\left.G_{I c}\right|_{f t}=133 ;\left.G_{I c}\right|_{f c}=40.0$ \\
energies $\left(\mathrm{kJ} / \mathrm{m}^{2}\right)$ & $\left.G_{I c}\right|_{m t}=1.7 ;\left.G_{I c}\right|_{m c}=2.0$ & $\left.G_{I c}\right|_{m t}=0.5 ;\left.G_{I c}\right|_{m c}=1.6$ \\
Interlaminar fracture energies $\left(\mathrm{kJ} / \mathrm{m}^{2}\right)$ & $G_{I c}=1.7 ; G_{I I c}=2.0$ & $G_{I c}=0.5 ; G_{I I c}=1.6$ \\
Benzeggagh-Kenane coefficient & $\eta=1.09$ & $\eta=1.45$ \\
$\quad$ & & $\sigma_{n}^{0}=43.0 ; \tau_{s}^{0}=\tau_{t}^{0}=50.0$ \\
mixed-mode exponent & $\sigma_{n}^{0}=43.0 ; \tau_{s}^{0}=\tau_{t}^{0}=50.0$ & $k=6.4 \times 10^{5}$ \\
Initial cohesive law stiffness $(\mathrm{MPa} / \mathrm{mm})$ & $k=6.4 \times 10^{5}$ & \\
\hline
\end{tabular}



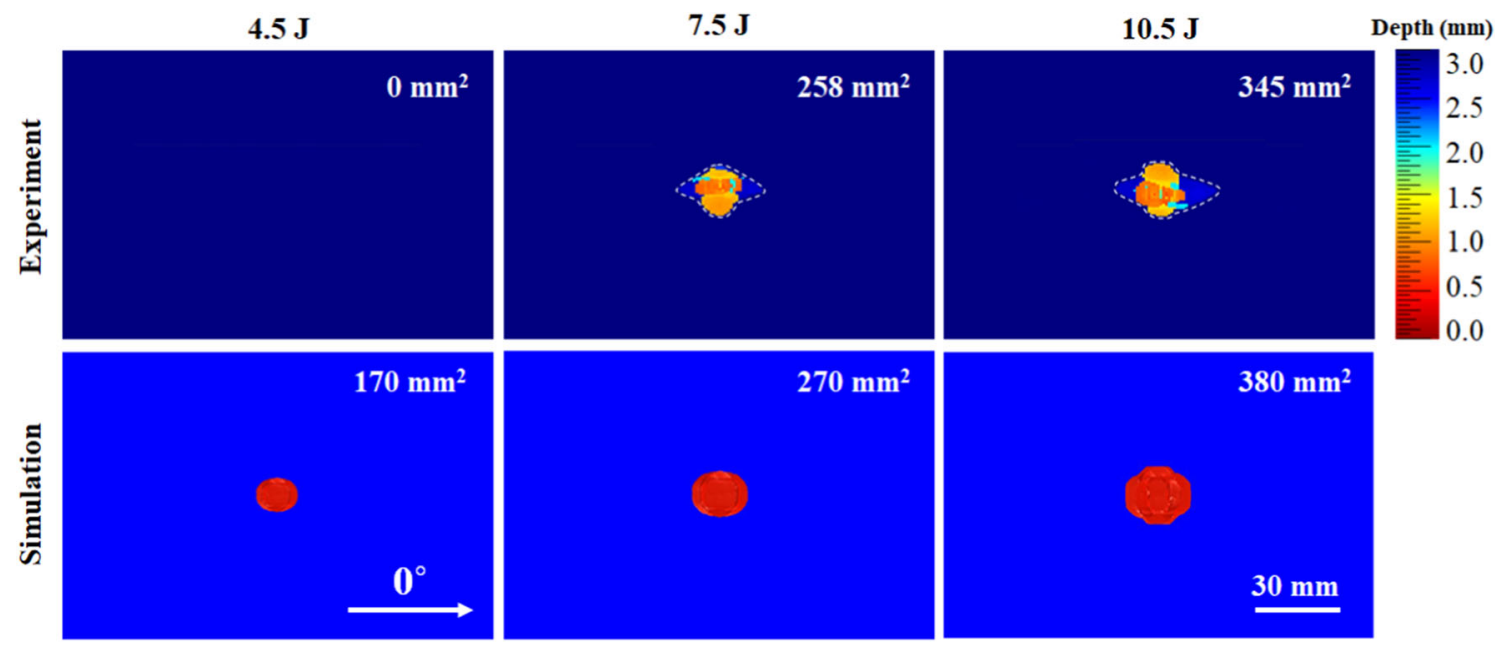

Figure 12 Experimental and simulated (red-coloured) footprints of the damage area for the CF/PEEK composite specimens for impact energies of $4.5,7.5$ and $10.5 \mathrm{~J}$ for the low-velocity drop- weight impact test. (See Fig. 6 for the explanation of the experimental C-scan depth scale, etc.).
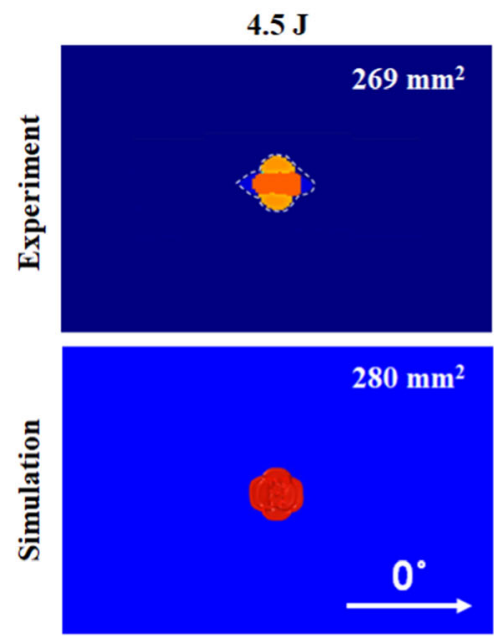

Figure 13 Experimental and simulated (red-coloured) footprints of the damage area for the $\mathrm{CF} /$ Epoxy composite specimens for impact energies of $4.5,7.5$ and $10.5 \mathrm{~J}$ for the low-velocity drop-

generally in good agreement with the damage maps that were experimentally measured using C-scan. The shapes and the locations of the damage areas from the modelling studies are also in good agreement with the experimental results. The one exception to this good agreement between the modelling and experimental results is the prediction of delamination occurring in the CF/PEEK composite specimen at an impact energy of $4.5 \mathrm{~J}$, when none was experimentally observed; see Fig. 12. This was most likely due to the predicted stress required to initiate such damage, as deduced from Eq. (16), at the lowest impact energy used for the CF/PEEK composite
$7.5 \mathrm{~J}$
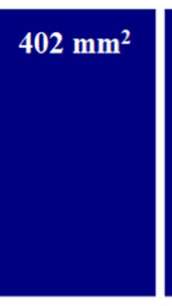

$410 \mathrm{~mm}^{2}$

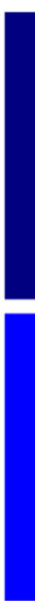

$10.5 \mathrm{~J}$

Depth (mm)

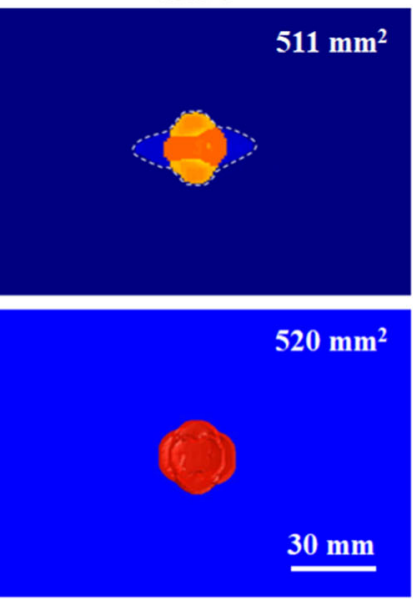

weight impact test. (See Fig. 6 for the explanation of the experimental C-scan depth scale, etc.).

being somewhat lower than that actually required. Hence, interlaminar delamination is predicted when none is actually observed experimentally at the lowest values of impact velocity and energy used in the present study. Further, as may be seen, the FE model lacks the fidelity to reproduce the exact shape of the experimentally measured delaminations. Nevertheless, the quantitative predictions of the locations and extent of damage areas obtained from the FE simulations demonstrate that the proposed model has the capability to predict reasonably well the overall delaminations due to a low-velocity impact. 
The modelling results for the typical evolution of interlaminar (i.e. delamination) damage in the CF/ PEEK composite specimens subjected to the dropweight impact test are presented in the timescale series of images in Fig. 14a as a series of cross-sectional images obtained from the simulations at an impact velocity and energy of $2.56 \mathrm{~m} . \mathrm{s}^{-1}$ and $10.5 \mathrm{~J}$, respectively. The damage evolution of intralaminar (i.e. matrix) damage in the CF/PEEK composite specimen for the same test conditions is shown in Fig. 14b. The intralaminar matrix damage, such as matrix cracking, arises from transverse stresses acting perpendicular to the fibres in the plies and there were no predictions of fibre failure from the modelling studies during either the low-velocity, or the highvelocity, impact tests. Therefore, it appears that the stresses induced in the plies are insufficiently high to cause fibre failure, which is in agreement with the experimental observations of the tested composite specimens. Finally, an interesting point to note is that the intralaminar matrix damage under the impactor is much more localised than the corresponding delamination damage.
The load versus time curves obtained from the modelling studies and the experimental tests for the $\mathrm{CF} / \mathrm{PEEK}$ and CF/Epoxy composites are compared in Figs. 15 and 16, respectively. A very good agreement is obtained between the experimental and modelling results for all three energy levels for both types of composite. Indeed, the modelling results even capture the small amplitude, sinusoidal oscillations on the rising part of load versus time curves which are indicative of mass-spring oscillations [22-24], as discussed earlier. The key experimental and numerical modelling results are compared in Table 6 and these results highlight the good agreement for both types of composite. Indeed, the modelling studies clearly agree with the experimental observations that the CF/PEEK composite, when impacted at these relatively low velocities, suffers significantly less damage than the CF/Epoxy composite when the results are compared at the same energy level.
Delamination damage

$$
0 \mathrm{~ms}
$$

$2.4 \mathrm{~ms}$
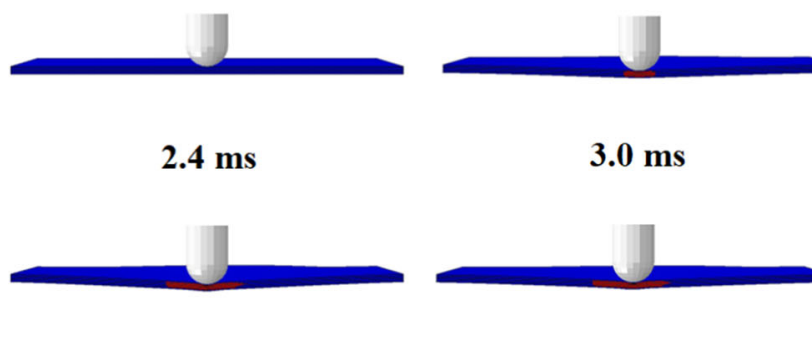

$0.6 \mathrm{~ms}$
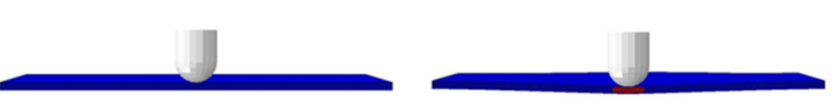

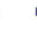

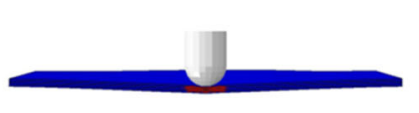

$3.6 \mathrm{~ms}$

$4.2 \mathrm{~ms}$

(a)

Matrix damage

$0 \mathrm{~ms}$

$0.6 \mathrm{~ms}$

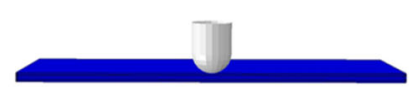

$2.4 \mathrm{~ms}$

$3.0 \mathrm{~ms}$
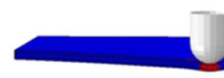

$1.2 \mathrm{~ms}$

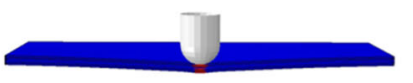

$3.6 \mathrm{~ms}$

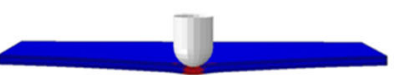

(b)

Figure 14 Simulations of the a interlaminar delamination (redcoloured) damage and $\mathbf{b}$ intralaminar matrix (red-coloured) damage as a function of timescale for the CF/PEEK composites for low-velocity drop-weight tests at an impact energy and velocity of $10.5 \mathrm{~J}$ and $2.56 \mathrm{~m} \mathrm{~s}^{-1}$, respectively. 


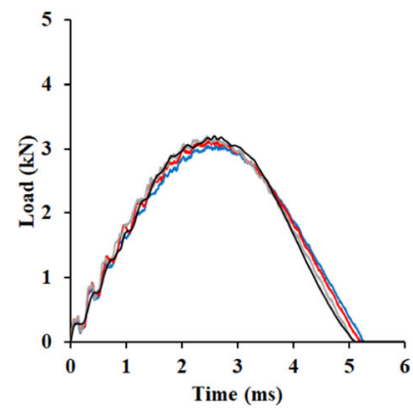

(a)

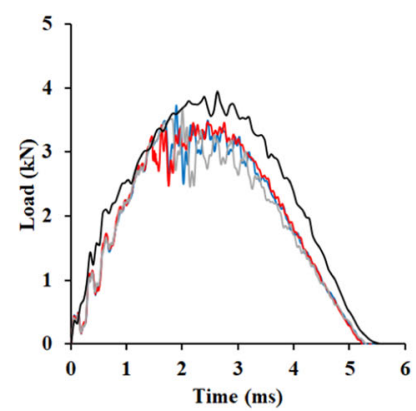

(b)

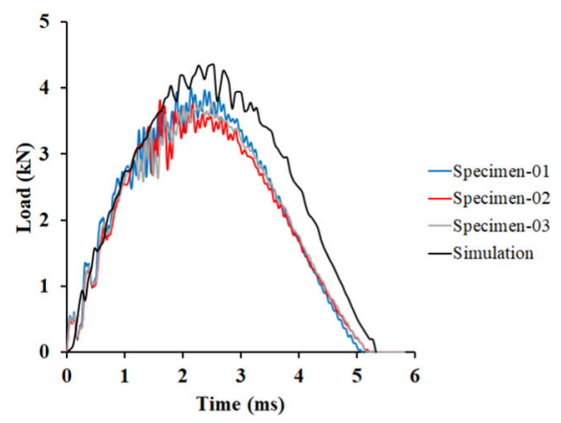

(c)

Figure 15 Experimental and simulated load versus time curves for the low-velocity drop-weight tests for the CF/PEEK composite specimens for: a 4.5 , b 7.5 and c $10.5 \mathrm{~J}$ impact energy levels.

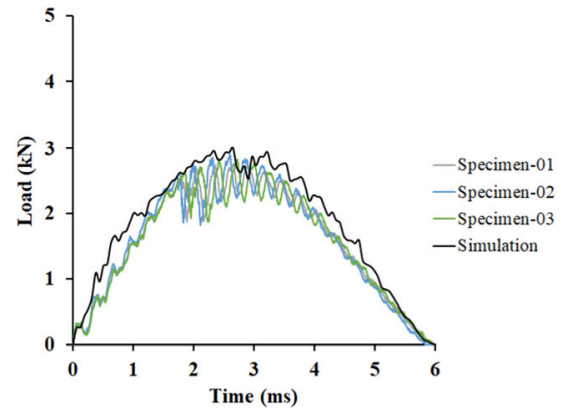

(a)

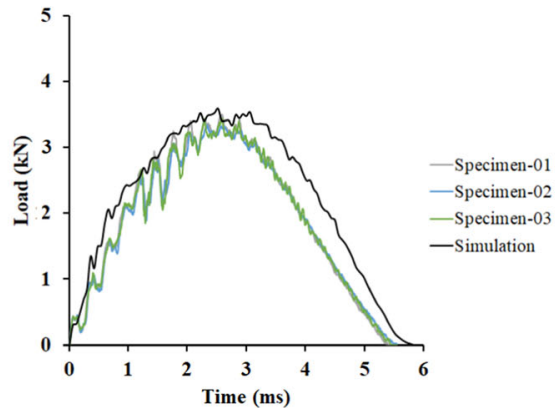

(b)

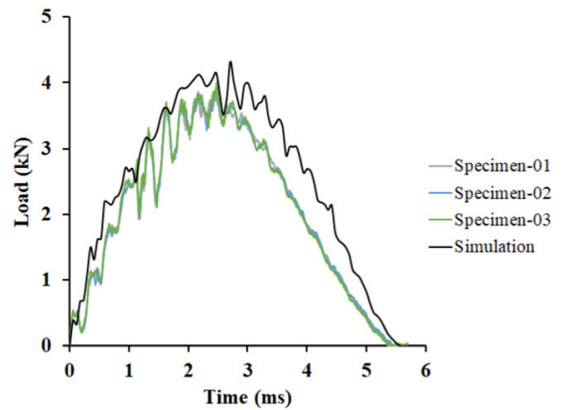

(c)

Figure 16 Experimental and simulated load versus time curves for the low-velocity drop-weight tests for the CF/Epoxy composite specimens for: a 4.5 , b 7.5 and c $10.5 \mathrm{~J}$ impact energy levels.

Table 6 Comparison of the experimental and numerically simulated results obtained from the low-velocity drop-weight tests at an impact energy and velocity of $10.5 \mathrm{~J}$ and $2.56 \mathrm{~m} \mathrm{~s}^{-1}$, respectively. (The error given is the coefficient of variation from the replicate experiments.)

\begin{tabular}{|c|c|c|c|c|}
\hline & \multicolumn{2}{|l|}{ CF/PEEK } & \multicolumn{2}{|l|}{ CF/Epoxy } \\
\hline & Experiment & Simulation & Experiment & Simulation \\
\hline Maximum load $(\mathrm{kN})$ & $3.9 \pm 3 \%$ & 4.3 & $3.9 \pm 2 \%$ & 4.2 \\
\hline Average area of the damage footprint $\left(\mathrm{mm}^{2}\right)$ & $335 \pm 5 \%$ & 380 & $517 \pm 6 \%$ & 580 \\
\hline
\end{tabular}

\section{Simulations of the high-velocity gas-gun impact test results}

Many researchers, for example [43-45], have shown that there can be a reduction in the values of the interlaminar fracture energies for such composite materials of up to about $20 \%$ when the strain rate is increased from quasi-static test conditions (i.e. about $10^{-3}$ to $10^{0} \mathrm{~s}^{-1}$ ) to high-velocity impact velocities of about $55 \mathrm{~m} \mathrm{~s}^{-1}$, which in the present tests correspond to a strain rate of about $300 \mathrm{~s}^{-1}$. (It was possible to extract from the DIC experimental results the maximum strain experienced by the composite specimens, and from knowing the timescale of the impact event, this information gives a strain rate of about $250 \mathrm{~s}^{-1}$ for the CF/PEEK and about $350 \mathrm{~s}^{-1}$ for the CF/Epoxy composite test specimens when struck by a rigid impactor at a velocity of about $55 \mathrm{~m} \mathrm{~s}^{-1}$.) As no fibre breakage was observed, or predicted, in the impacted composite specimens, only the interlaminar and matrix ply fracture energies, for both Mode I and Mode II failure, were decreased in the present models of the high-velocity impact tests. Now, from the literature [43-45] on the effects of 
strain rate on the properties of composite laminates, it is considered that for these high-velocity tests a reduction in the values of the interlaminar and matrix fracture energies of about $20 \%$ should be made to account for this strain rate effect. Thus, two different sets of values for the values of the interlaminar and matrix ply fracture energies were considered for use in the simulations, i.e. $100 \%$ and $80 \%$ of the quasistatic values of $\left.G_{I c}\right|_{m t},\left.G_{I c}\right|_{m c}, G_{I c}$ and $G_{I I c}$ given in Table 5.

In the simulations of the gas-gun impact tests, an impact velocity of $54.4 \mathrm{~m} \mathrm{~s}^{-1}$ was employed which gives an impact energy of $10.5 \mathrm{~J}$. The simulations of the gas-gun tests were performed for both the CF/ PEEK and the CF/Epoxy composite specimens. The simulation results were obtained from the FE numerical model with the two different levels of fracture energy values, as noted above. The predicted damage footprints are shown in Fig. 17, together with the experimentally measured C-scan damage maps. The modelling results accurately predict that (a) the damage areas in the composites are always significantly higher from the high-velocity gas-gun tests than from the low-velocity drop-weight tests, at the same impact energy of $10.5 \mathrm{~J}$, see Figs. 13 and 17, and (b) the CF/Epoxy composite undergoes somewhat greater damage compared with the CF/PEEK composite. However, the results shown in Fig. 17 reveal that the areas of the damage footprints predicted by the FE model using the quasi-static fracture energies are smaller than those obtained from the experiments. Obviously, as expected, the models using the reduced values of $80 \%$ of the fracture energies give larger footprints of the damage areas and these simulation results are in somewhat better agreement
Figure 17 Experimental and simulated (red-coloured) footprints of the damage areas for the CF/PEEK and $\mathrm{CF}$ / Epoxy composite specimens from the high-velocity gas-gun test using an impact energy and velocity of $10.5 \pm 0.3 \mathrm{~J}$ and $54.4 \pm 1.0 \mathrm{~m} \mathrm{~s}^{-1}$, respectively. (See Fig. 6 for the explanation of the experimental C-scan depth scale, etc. Results are shown for both $100 \%$ and $80 \%$ of the quasi-static interlaminar and matrix fracture energies.)
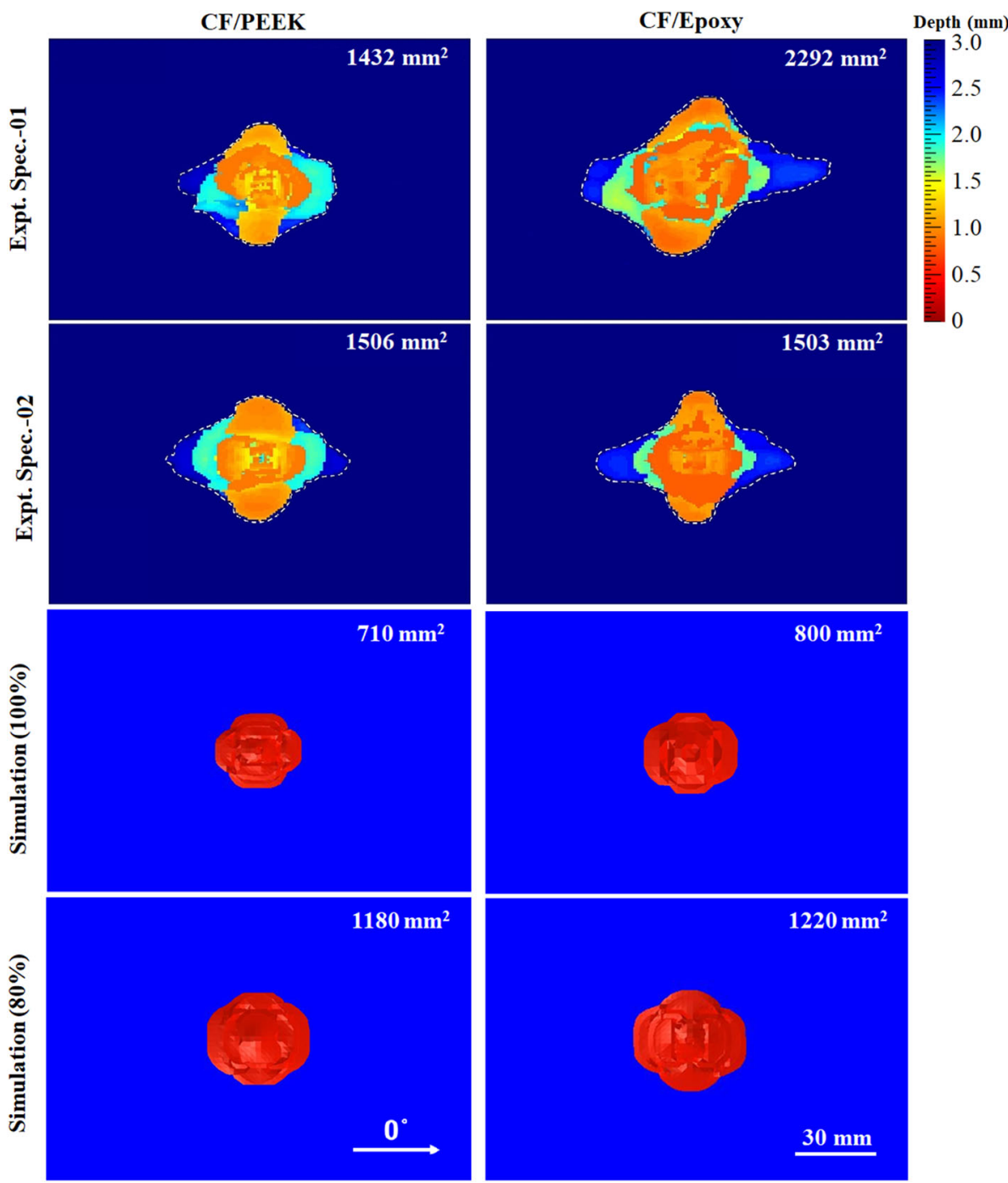
with the experimental results. However, the simulations shown in Fig. 17 reveal that, even when using $80 \%$ of the quasi-static fracture energies, the footprints of the predicted damage areas are always lower than the values measured experimentally from the C-scans tests. This is likely to arise from several factors. Firstly, in the high-velocity model simulations, only the interlaminar and matrix ply fracture energies were reduced to $80 \%$ of their quasi-static values and the other material properties required for the model were kept at their quasi-static values. This was done since the fracture energies have been shown to decrease at relatively high strain rates [43-45] and the fibre-dominated properties would certainly be expected to show relatively little change as the strain rate is increased. Secondly, without a detailed knowledge of the strain rate effects for the other material properties, it was considered best to keep all the other material properties at their quasistatic values for consistency. Thirdly, in the model, the presence of intralaminar matrix fracture damage is considered to lead to a reduction in stiffness of the elasticity matrix, i.e. the term $C_{d}$ as defined by implementing Eqs. 10 to 14, which represents damage of the ply elements. Thus, intralaminar matrix cracks, as such, are not physically present in this 'smeared crack' model but only their effects on the ply element stiffnesses. However, in the experiments, intralaminar matrix cracks could be diverted at the ply interfaces to then generate more interlaminar delaminations and this may aspect also account for the extra extent of delamination that was experimentally observed.

The FE model, using the $80 \%$ of the values of the quasi-static fracture energies, was also employed to predict the values of the out-of-plane displacement, and the results are compared to the experimental values from the DIC tests, as shown in Fig. 18. As may be seen, good agreement is obtained between the experimental and simulation results. Furthermore, the predicted maximum out-of-plane displacements of $3 \mathrm{~mm}$ for the CF/PEEK and $3.5 \mathrm{~mm}$ for the CF/ Epoxy composite are in very good agreement with the maximum values of $3 \mathrm{~mm}$ and $3.4 \mathrm{~mm}$, respectively, that were experimentally measured; see Fig. 8 . It should be noted that the deflection of the specimen by the impactor is a structural response of the specimen to the loading by the impactor, and as such, it would not be expected to be strongly affected by the reduction in the quasi-static fracture energies. To confirm this, the out-of-plane displacements were also determined at $100 \%$ of the quasi-static fracture energies and it was indeed found that the displacements of the composite specimens are virtually identical to those predicted when using only $80 \%$ of the quasi-static fracture energies in the model. Thus, although the composite specimens are damaged by the delaminations that occurred, their overall structural responses are not dramatically modified, as is indeed confirmed by these modelling results.

For these high-velocity impact tests, the load versus time curves of the CF/PEEK and CF/Epoxy composites could not be experimentally measured, as discussed earlier. Notwithstanding, the numerical model, which has been confirmed by the experimental results, i.e. the C-scan damage and DIC displacement maps, has been employed to predict the load versus time curves, as shown in Fig. 19. Now, the deceleration of the rigid impactor was a measured output and was employed in the simulation to calculate the load on the rigid impactor, based on Newton's second law, i.e. $F=m a$, where $F$ is the load of the impactor, $m$ is the mass of the impactor and $a$ is the acceleration of the impactor. Major oscillations in the load were predicted to occur in the simulations of the load versus time curves, see Fig. 19, and the predicted curves exhibit major two load peaks, which are somewhat sensitive to a reduction in the values of the fracture energies. In Fig. 19a for the CF/PEEK composite, both the load peaks are seen to decrease when the interlaminar and matrix fracture energies are reduced to $80 \%$ of the quasi-static values in the modelling studies. However, in Fig. 19b for the CF/ Epoxy composite, only the first load peak substantially decreases when the interlaminar and matrix fracture energies are reduced to $80 \%$ of the quasistatic values in the model, albeit a relatively small decrease is also seen in the second load peak. This slight difference in the predicted behaviour for the $\mathrm{CF} / \mathrm{PEEK}$ and CF/Epoxy composites may possibly be related to fracture energy effects in the modelling results. Notwithstanding, considering the basic underlying causes of these major oscillations in the predicted load versus time responses, then from previous studies [46, 47] it is considered that they arise from dynamic effects. Thus, the presence of the first major peak in Fig. 19a, b is considered to be due to the initial rapid acceleration of the composite specimen upon being struck by the impactor, which then leads to a temporary loss of contact between the 


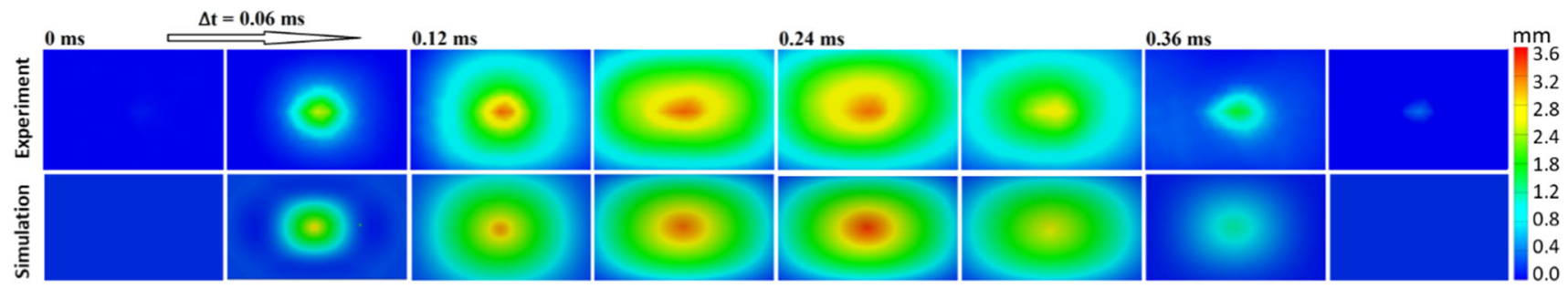

(a)

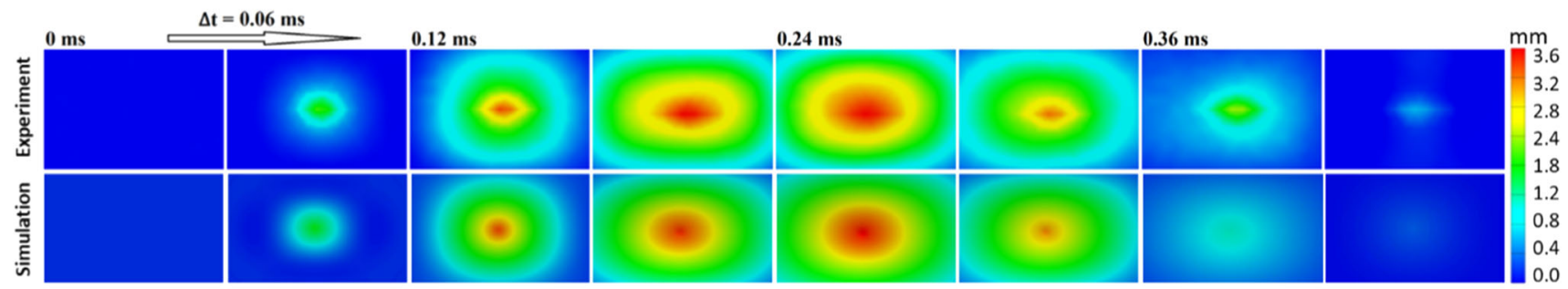

(b)

Figure 18 Experimental and simulated out-of-plane displacement maps obtained from $\mathbf{a}$ the CF/PEEK and $\mathbf{b}$ the CF/Epoxy composite specimens when subjected to the high-velocity gas-

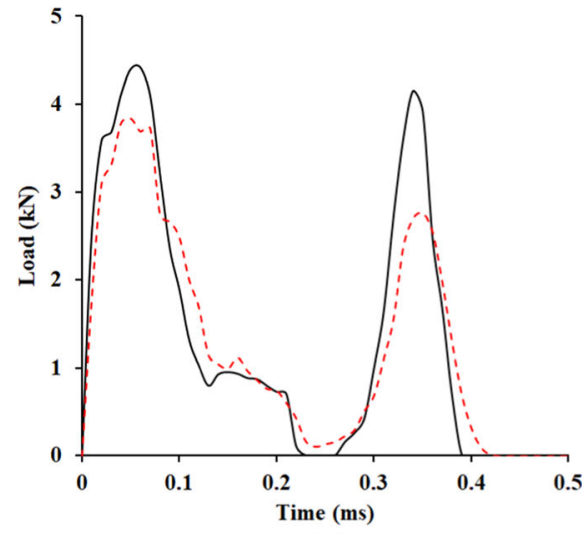

(a)

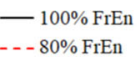

Figure 19 Load versus time curves as predicted from the FE model for: $\mathbf{a}$ the $\mathrm{CF} / \mathrm{PEEK}$ and $\mathbf{b}$ the $\mathrm{CF} /$ Epoxy composite specimens subjected to a high-velocity gas-gun test at an impact

impactor and the specimen. In the load versus time curves, this temporary loss of contact is reflected as a load drop. The velocity imparted to the composite specimen then decreases and the impactor strikes the composite specimen for a second time, and there is now a further phase of an increase in the load on the composite specimen, as evidenced by the second major load peak. Damage in the composite specimen occurs during and just after both impacts. The load versus time impulse (i.e. the area under load versus time curve) is about $0.6 \mathrm{~N} \mathrm{~s}$ which will be responsible for the total change in momentum of the incoming gun test at an impact energy and velocity of $10.5 \pm 0.3 \mathrm{~J}$ and $54.4 \pm 1.0 \mathrm{~m} \mathrm{~s}^{-1}$, respectively.

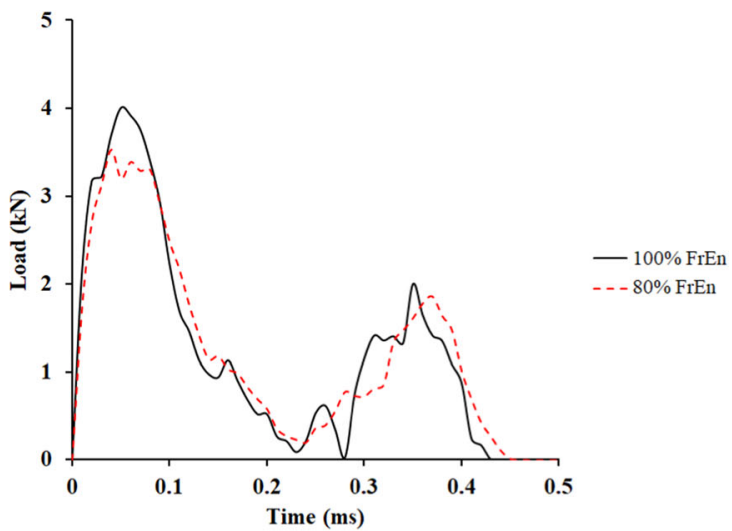

(b)

energy and velocity $10.5 \mathrm{~J}$ and $54.4 \mathrm{~m} \mathrm{~s}^{-1}$, respectively. (Results are shown for using $100 \%$ and $80 \%$ of the quasi-static interlaminar and matrix fracture energies (FrEn)).

impactor. The total change in momentum would therefore be expected to be $0.6 \mathrm{~kg} \mathrm{~m} \mathrm{~s}^{-1}$ during the impact event. The incoming momentum of the impactor is $0.38 \mathrm{~kg} \mathrm{~m} \mathrm{~s}^{-1}$, and so, it would be expected that the impactor would rebound with momentum of about $0.22 \mathrm{~kg} \mathrm{~m} \mathrm{~s}^{-1}$. This implies that the rebound velocity of the impactor at the end of the impact event would be about $60 \%$ of the impact velocity. This parameter was not measured accurately, but this value is consistent with the significant rebound that was observed. Thus, the gas-gun, and also the drop-weight, impact events were reasonably 
elastic in nature with a high proportion of kinetic energy being returned to the impactor.

\section{Conclusions}

The impact behaviour of a thermoplastic CF/PEEK composite and a toughened thermoset CF/Epoxy composite, which possessed the same cross-ply layup of $\left[0_{3} / 90_{3}\right]_{2 s}$, has been investigated. The relatively low-velocity impact experiments, at impact velocities of $1.68,2.16$ and $2.56 \mathrm{~m} \mathrm{~s}^{-1}$ giving impact energies of $4.5,7.5$ and $10.5 \mathrm{~J}$, were carried out using a dropweight test. For the high-velocity experiments, a gasgun was employed using an impact velocity of $54.4 \pm 1.0 \mathrm{~m} \mathrm{~s}^{-1}$ which resulted in an impact energy of $10.5 \pm 0.3 \mathrm{~J}$. In all the tests a rigid, metallic impactor was used with a hemisphere-shaped head. The damage inflicted in the composites was assessed by both a visual inspection and by ultrasonic C-scanning. Furthermore, an elastic, two-dimensional finite element (FE) model has been developed to simulate the results obtained from both the low-velocity and high-velocity impact tests. The model, which is relatively computationally efficient, has been shown to simulate (a) the loading responses of the composites by the impact event and (b) the interlaminar and intralaminar damage induced.

For the low-velocity drop-weight tests, the experimental results demonstrated that, at the same impact energy, the CF/PEEK composite always possessed a superior impact performance compared with the CF/ Epoxy. This was reflected by the CF/PEEK composite requiring a higher load to initiate damage and a smaller area of delamination damage being present in the CF/PEEK composite post-impact. The results from the FE model for the load versus time curves from all the tests were in very good agreement with the experimental measurements and even captured the small amplitude, sinusoidal oscillations on the rising part of the load versus time curves which are indicative of mass-spring oscillations.

In the high-velocity tests using the gas-gun, the results revealed that the CF/PEEK and CF/Epoxy composites exhibited a similar damage pattern with values of the average damage area of $1462 \pm 37 \mathrm{~mm}^{2}$ and $1898 \pm 395 \mathrm{~mm}^{2}$, respectively. Thus, the CF/ Epoxy composite clearly exhibits the higher average damage area, but with a significantly larger degree of scatter. Furthermore, these damage areas are significantly greater than those recorded for the lowvelocity drop-weight test, at the same impact energy of $10.5 \pm 0.3 \mathrm{~J}$, for both types of composite. The outof-plane displacements of the composite specimens were measured as a function of time during the impact event with the maximum values being approximately $3 \mathrm{~mm}$ for the CF/PEEK composite and $3.4 \mathrm{~mm}$ for the CF/Epoxy composite. Considering the FE modelling of the high-velocity tests, the simulations have accurately predicted (a) the shape and values of the out-of-plane displacements as a function of the timescale of the impact event, (b) that the damage areas in the composites were always significantly higher from the high-velocity gas-gun tests than from the low-velocity drop-weight tests, at a comparable impact energy of $10.5 \mathrm{~J}$, and (c) that the $\mathrm{CF} /$ Epoxy composite suffered somewhat greater damage compared with the CF/PEEK composite. However, the actual footprints of the damage areas predicted from the modelling studies for the highvelocity tests were always somewhat lower than the values measured experimentally from the C-scans tests, and reasons for this have been proposed. For these high-velocity impact tests, the load versus time curves of the CF/PEEK and CF/Epoxy composites could not be experimentally measured; nevertheless, they were predicted using the FE model. The presence of two major peaks in the load versus time curves has been identified and ascribed to the initial rapid acceleration of the specimen upon being struck by the impactor. This rapid loading leads to a temporary loss of contact between the impactor and the composite specimen which is then followed by contact being re-established when there is a further phase of loading, before the impactor finally rebounds at the end of the impact event at about $60 \%$ of its impact velocity,

Therefore, the present detailed study has revealed the effects of the impact energy and velocity on the behaviour of a thermoplastic and a toughened thermoset matrix CFRP composite, where both have the same cross-ply fibre architecture. A two-dimensional, elastic, FE numerical model has been developed which is relatively computationally efficient. The results from this model has been quantitatively validated against the impact response of the composites and captures the essential aspects of their impact behaviour and can be used (a) to simulate aspects of the high-velocity tests that cannot be directly 
measured and (b) to optimise the impact performance of such materials in industrial applications.

\section{Acknowledgements}

The strong support from the Aviation Industry Corporation of China (AVIC), the First Aircraft Institute (FAI) and the Manufacturing Technology Institute (MTI) of the People's Republic of China for funding research is much appreciated. The research was performed at the AVIC Centre for Structural Design and Manufacture at Imperial College London. Dr. Jun Liu very much appreciates the support and advice provided by Dr. Xingyun Ma and Dr. Wengui Wang of AVIC Composite Corporation and by Beian, People's Republic of China, for the use of the autoclave to manufacture the CF/Epoxy specimens.

\section{Compliance with ethical standards}

Conflict of interest The authors declare no conflicts of interest.

Open Access This article is licensed under a Creative Commons Attribution 4.0 International License, which permits use, sharing, adaptation, distribution and reproduction in any medium or format, as long as you give appropriate credit to the original author(s) and the source, provide a link to the Creative Commons licence, and indicate if changes were made. The images or other third party material in this article are included in the article's Creative Commons licence, unless indicated otherwise in a credit line to the material. If material is not included in the article's Creative Commons licence and your intended use is not permitted by statutory regulation or exceeds the permitted use, you will need to obtain permission directly from the copyright holder. To view a copy of this licence, visit http://creativecommons.org/licen ses/by/4.0/.

\section{References}

[1] Cogswell FN (1992) Thermoplastic aromatic polymer composites. Butterworth Heinemann, Oxford

[2] Cantwell WJ, Morton J (1985) Detection of impact damage in CFRP laminates. Compos Struct 3:241-257
[3] Dorey G, Bishop SM, Curtis PT (1985) On the impact performance of carbon fibre laminates with epoxy and PEEK matrices. Compos Sci Tech 23:221-237

[4] Bishop S (1985) The mechanical performance and impact behaviour of carbon-fibre reinforced PEEK. Compos Struct $3: 295-318$

[5] Nixon JA, Phillips MG, Moore DR, Prediger RS (1988) A study of the development of impact damage in cross-ply carbon-fibre/PEEK laminates using acoustic emission. Compos Sci Tech 31:1-14

[6] Cantwell WJ, Morton J (1989) Comparison of the low and high velocity impact response of CFRP. Compos 20:545-551

[7] Cantwell WJ, Morton J (1989) The influence of varying projectile mass on the impact response of CFRP. Compos Struct 13:101-114

[8] Ghaseminejhad MN, Parvizi-Majidi A (1990) Impact behaviour and damage tolerance of woven carbon fibre-reinforced thermoplastic composites. Constr Build Mater 4:194-207

[9] Cantwell WJ, Morton J (1991) The impact resistance of composite materials - a review. Comp 22:347-362

[10] Lammerant L, Verpoest I (1996) Modelling of the interaction between matrix cracks and delaminations during impact of composite plies. Compos Sci Tech 56:1171-1178

[11] Shi Y, Swait T, Soutis C (2012) Modelling damage evolution in composite laminates subjected to low velocity impact. Compos Struct 94:2902-2913

[12] Vieille B, Casado VM, Bouvet C (2013) About the impact behavior of woven-ply carbon fiber-reinforced thermoplastic- and thermosetting-composites: a comparative study. Compos Struct 101:9-21

[13] Liu H, Falzon BG, Tan W (2018) Experimental and numerical studies on the impact response of damage-tolerant hybrid unidirectional/woven carbon-fibre reinforced composite laminates. Compos Part B Eng 136:101-118

[14] Heimbs S, Bergmann T (2012) High-velocity impact behaviour of prestressed composite plates under bird strike loading. Int J Aerosp Eng. https://doi.org/10.1155/2012/ 372167

[15] Liu J, Liu H, Kaboglu C, Kong X, Ding Y, Chai H, Blackman BRK, Kinloch AJ, Dear JP (2019) The impact performance of woven-fabric thermoplastic and thermoset composites subjected to high-velocity soft- and hard-impact loading. Appl Compos Mater 26:1389-1410

[16] Liu H, Liu J, Kaboglu C, Chai H, Kong X, Blackman BRK, Kinloch AJ, Dear JP (2020) Experimental investigations on the effects of projectile hardness on the impact response of fibre reinforced composite laminates. Int $\mathrm{J}$ Lightweight Mater Manuf 3:77-87 
[17] Liu H, Liu J, Kaboglu C, Zhou J, Kong X, Blackman BRK, Kinloch AJ, Dear JP (2020) The behaviour of fibre-reinforced composites subjected to a soft impact-loading: an experimental and numerical study. Eng Fail Anal 111:104448. https://doi.org/10.1016/j.engfailanal.2020

[18] Morita H, Adachi T, Tatesiha Y, Matsumoto H (1997) Characterization of impact damage resistance of CF/PEEK and $\mathrm{CF}$ /Toughened epoxy laminates under low and high velocity tests. J Reinf Plastics Compos 16:131-143

[19] Wagner T, Heimbs S, Franke F, Burger U, Middendorf P (2018) Experimental and numerical assessment of aerospace grade composites based on high-velocity impact experiments. Compos Struct 204:142-152

[20] ASTM (2014) Standard test method for measuring the damage resistance of a fiber-reinforced polymer matrix composite to a drop-weight impact event. D7136/D7136M05, West Conshohocken, PA

[21] Liu J (2020) The performance of thermoplastic and thermoset composites subjected to impact loading. PhD Thesis. Imperial College London, UK

[22] Dear JP, MacGillivray JH (1991) Strain gauging for accurate determination of $\mathrm{K}$ and $\mathrm{G}$ in impact tests. $\mathrm{J}$ Mater Sci 26:2124-2132. https://doi.org/10.1007/BF00549178

[23] Crouch BA, Williams JG (1988) Modelling of dynamic crack propagation behaviour in the three-point bend impact specimen. J Mech Phys Solids 36:1-13

[24] Williams JG, Adams GC (1987) The analysis of instrumented impact tests using a mass-spring model. Int J Fract 33:209-222

[25] Abaqus (2018) Documentation. Dassault Systèmes. Provid Rhode Island, USA

[26] Tan W, Falzon BG (2016) Modelling the crush behaviour of thermoplastic composites. Compos Sci Technol 134:57-71

[27] Chiu LNS, Falzon BG, Chen B, Yan W (2016) Validation of a 3D damage model for predicting the response of composite structures under crushing loads. Compos Struct 147:65-73

[28] Hashin Z, Rotem A (1973) A fatigue failure criterion for fiber reinforced materials. J Compos Mater 7:448-464

[29] Hashin Z (1980) Failure criteria for unidirectional fiber composites. J Appl Mech 47:329-334

[30] Liu H, Falzon BG, Li S, Tan W, Liu J, Chai H, Blackman BRK, Dear JP (2019) Compressive failure of woven fabric reinforced thermoplastic composites with an open-hole: an experimental and numerical study. Compos Struct 213:108-117

[31] Faggiani A, Falzon BG (2010) Predicting low-velocity impact damage on a stiffened composite panel. Compos Part A Appl Sci Manuf 41:737-749

[32] Dugdale DS (1960) Yielding of steel sheets containing slits. J Mech Phys Solids 8:100-104
[33] Barenblatt G (1962) The mathematical theory of equilibrium cracks in brittle fracture. Adv Appl Mech 7:55-129

[34] Shi Y, Pinna C, Soutis C (2014) Interface cohesive elements to model matrix crack evolution in composite laminates. Appl Compos Mater 21:57-70

[35] Shi Y, Pinna C, Soutis C (2014) Modelling impact damage in composite laminates: a simulation of intra- and inter-laminar cracking. Compos Struct 114:10-19

[36] Turon A, Dávila CG, Camanho PP, Costa J (2007) An engineering solution for mesh size effects in the simulation of delamination using cohesive zone models. Eng Fract Mech 74:1665-1682

[37] Brewer JC, Lagace PA (1988) Quadratic stress criterion for initiation of delamination. J Compos Mat 22:1141-1196

[38] Benzeggagh ML, Keane M (1996) Measurement of mixedmode delamination fracture toughness of unidirectional glass/epoxy composites with mixed-mode bending apparatus. Compos Sci Tech 56:439-449

[39] Camanho PP, Vila CGD, De Moura MF, Camanho PP, Davila CG, De Moura MF (2003) Numerical simulation of mixed-mode progressive delamination in composite materials. J Compos Mater 37:1415-1438

[40] Sarrado C, Turon A, Renart J, Urresti I (2012) Assessment of energy dissipation during mixed-mode delamination growth using cohesive models. Compos Part A Appl Sci Manuf 43:2128-2136

[41] Hashemi S, Kinloch AJ, Williams JG (1990) The analysis of interlaminar fracture in uniaxial fibre-polymer composites. Proc R Soc A427:173-199

[42] Abir MR, Tay TE, Ridha M, Lee HP (2017) On the relationship between failure mechanism and compression after impact (CAI) strength in composites. Compos Struct 182:242-250

[43] Blackman BRK, Dear JP, Kinloch AJ, MacGillivray H, Wang Y, Williams JG (1995) The failure of fibre-composites and adhesively-bonded fibre-composites under high rates of test, part I: mode I loading - experimental studies. J Mater Sci 30:5885-5900. https://doi.org/10.1007/BF01151502

[44] Blackman BRK, Kinloch AJ, Wang Y, Williams JG (1996) The failure of fibre composites and adhesively bonded fibre composites under high rates of test, part II: mode I loadingdynamic effects. J Mater Sci 31:4451-4466. https://doi.org/ 10.1007/BF00366341

[45] Blackman BRK, Dear JP, Kinloch AJ, MacGillivray H, Wang Y, Williams JG (1996) The failure of fibre-composites and adhesively-bonded fibre-composites under high rates of test, part III: mixed-mode loading I/II and mode II loadings. J Mater Sci 31:4467-4477. https://doi.org/10.1007/ BF00366341 
[46] Kinloch AJ, Kodokian GA, Jamarani MB (1987) Impact properties of epoxy polymers. J Mater Sci 22:4111-4120. h ttps://doi.org/10.1007/BF01133366

[47] Dear JP (1990) High speed photography of impact effects in three-point bend testing of polymers. J Appl Phys $67: 4304-4312$
Publisher's Note Springer Nature remains neutral with regard to jurisdictional claims in published maps and institutional affiliations. 